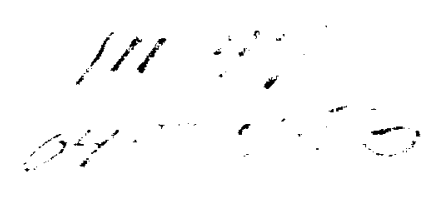

\title{
Variance and Predictability of Precipitation at Seasonal-to-Interannual Timescales
}

\author{
Randal D. Koster ${ }^{1}$, Max J. Suarez ${ }^{2}$, and Mark Heiser ${ }^{3}$ \\ ${ }^{1}$ Hydrological Sciences Branch, Laboratory for Hydrospheric Processes, \\ NASA/Goddard Space Flight Center, Greenbelt, MD, USA. \\ ${ }^{2}$ Climate and Radiation Branch, Laboratory for Atmospheres, \\ NASA/Goddard Space Flight Center, Greenbelt, MD, USA. \\ ${ }^{3}$ General Sciences Corporation, Beltsville, MD, USA.
}

Submitted to Journal of Hydrometeorology

February 10, 1999 


\begin{abstract}
A series of atmospheric general circulation model (AGCM) simulations, spanning a total of several thousand years, is used to assess the impact of land-surface and ocean boundary conditions on the seasonal-to-interannual variability and predictability of precipitation in a coupled modeling system. In the first half of the analysis, which focuses on precipitation variance, we show that the contributions of ocean, atmosphere, and land processes to this variance can be characterized, to first order, with a simple linear model. This allows a clean separation of the contributions, from which we find: (1) land and ocean processes have essentially different domains of influence, i.e., the amplification of precipitation variance by land-atmosphere feedback is most important outside of the regions (mainly in the tropics) that are most affected by sea surface temperatures; and (2) the strength of land-atmosphere feedback in a given region is largely controlled by the relative availability of energy and water there. In the second half of the analysis, the potential for seasonal-to-interannual predictability of precipitation is quantified under the assumption that all relevant surface boundary conditions (in the ocean and on land) are known perfectly into the future. We find that the chaotic nature of the atmospheric circulation imposes fundamental limits on predictability in many extratropical regions. Associated with this result is an indication that soil moisture initialization or assimilation in a seasonal-to-interannual forecasting system would be beneficial mainly in transition zones between dry and humid regions.
\end{abstract}




\section{Introduction}

Characterizing the variability of Earth's climate is extremely difficult given the paucity of relevant long-term data that span the globe. Various observing systems and programs have been implemented in response to this problem; the Global Precipitation Climatology Project [Arkin and Xie, 1994], for example, was established to provide global precipitation data over years to decades, and the recently initiated Global Climate Observing System [Karl et al., 1994] focuses on the proper long-term monitoring of all climate variables. Still, it will be some time before a multi-decadal climate record can be established that is spatially complete and error-free enough to allow comprehensive analyses of climate variability. Even when such a dataset is produced, it will necessarily lack direct measurements of important variables such as evaporation, which cannot be collected on the global scale.

The severe limitations inherent in the observational record have led many climatologists to rely in part on climate modeling systems such as atmospheric general circulation models (AGCMs). Such models are fraught, of course, with potential errors both in their atmospheric components [e.g., Cess et al., 1990; Alekseev et al., 1996; Boyle, 1998a] and their land surface components [e.g., Chen et al., 1997; Wood et al., 1998]. Nevertheless, provided that the climate simulated by an AGCM is similar enough to the observed climate, the AGCM offers two powerful advantages as a tool for

climate studies: (1) global coverage of all climate variables, over (in princi- 
ple) any time period of interest, and (2) the potential for integrations with artificially modified forcing and boundary conditions, for purposes of isolating and characterizing the mechanisms underlying climate variability. If the AGCM does produce a reasonable facsimile of the observed climate, then the gist of the findings from a numerical experiment should be valid. The errors inherent in an AGCM, though, must be acknowledged and used to qualify or temper such findings.

The climate variability studies that have been performed to date with AGCMs are so numerous that we can only touch on a small sample here. Early on, Manabe and Hahn [1981] characterized the temporal variability of surface pressure and temperature in the GFDL (Geophysical Fluid Dynamics Laboratory) AGCM using 15 years of simulation data. Delworth and Manabe $[1988,1989]$ analyzed a multi-decade integration of a later version of this AGCM to characterize the relationship between precipitation and soil moisture spectra and to establish a link between soil moisture variability and that of near surface temperature and humidity. Of particular recent interest is the far-field response of weather patterns to ENSO events in the tropical Pacific, a problem particularly amenable to examination with AGCMs [e.g., Strauss and Shukla, 1997; Davies et al., 1997; Lau and Bua, 1998]. Recent efforts to validate simulated variability against observations include detailed analyses [e.g., Bates and Jackson, 1997; Boyle, 1998b; Robock et al., 1998] of the 10-year simulations performed by many AGCMs as part of the Atmospheric 
Model Intercomparison Project (AMIP) [Gates, 1992].

The present paper extends our own climate variability studies [Koster and Suarez, 1995, 1996a, 1999], which mostly focus on quantifying the influence of land hydrology on precipitation variability. Of most relevance here is the work presented in Koster and Suarez [1995] (hereafter KS95), in which we quantified the relative contributions of sea surface temperatures (SSTs) and land surface hydrological state to the variance of continental precipitation on annual and seasonal timescales. Four numerical simulations were performed. The control simulation (ALO) included a fully coupled land surface model (LSM) and was forced with realistically varying SSTs. In the second simulation (AL), the influence of SST variability on the atmospheric circulation (and thus on precipitation) was "disabled" through the application of climatological SSTs, and in the third simulation (AO), the influence of an interactive land surface was disabled through the prescription of climatological evaporation efficiencies (see section 2.2 below). Both the land and the ocean influences were disabled in the fourth simulation (A). Figure 1 shows the main result of KS95. In this model, land surface processes generally contribute more to simulated continental precipitation variance than do variations in SSTs. We found that the land surface's contribution in midlatitudes is in fact greatest during summer, when convection processes are particularly sensitive to surface conditions.

Although we learned much from this study, the limited duration of the 
simulations (10 to 20 years) prevented a full analysis of precipitation variability. First, we could only grossly estimate precipitation variances, since only 10 or 20 data values could be used to generate statistics. Second, and more important, we were unable to establish the extent to which variable SSTs control the time-sequencing of precipitation anomalies - we hypothesized (but could not prove) that in many cases, SSTs control the timing of the anomalies, whereas land surface processes simply act to amplify them. Quantifying the control of SSTs on the timing of anomalies is of critical importance to establishing consistency between the results of KS95 and the (seemingly contradictory) conventional wisdom regarding the impact of time-varying SSTs on continental precipitation, which is supported by empirical analyses linking various precipitation anomalies to specific SST patterns. Furthermore, quantifying this control is critical to a proper characterization and evaluation of any seasonal-to-interannual prediction system that uses the AGCM. After all, useful predictions from such a system rely on the response of precipitation anomalies to predicted anomalies in the surface boundary conditions.

Addressing these and many other variability questions requires larger ensembles and substantially longer simulations than those performed in KS95. In response to this need, our coupled land-atmosphere model was recently recoded to take advantage of massively parallel processors and message passing techniques. This new version of the model has allowed us to take advantage of the computing power of a 512 processer CRAY T3E recently acquired 
to support NASA's Seasonal-to-Interannual Prediction Project (NSIPP). We can now increase tremendously the number and lengths of our simulations, opening the door to numerous new and valuable studies.

In the present study, we performed five 16-member ensembles of AGCM simulations that span a total of almost 4000 years. The resulting model fields and improved statistics allow new insight into how oceanic, atmospheric, and land surface processes affect precipitation variance at the annual timescale. They also allow a direct evaluation of precipitation predictability in the coupled system.

Section 2 below describes the models used and the design of the five ensembles, and section 3 presents an evaluation of model output against past results and observations. Our analyses of precipitation variance and predictability follow in sections 4 and 5 , respectively.

\section{AGCM Simulations}

\subsection{Models Used}

The ensembles of numerical experiments were performed with an updated version of the model used in KS95, a $4^{o} \times 5^{\circ}$ version of the GEOS-Climate (ARIES) AGCM. This AGCM includes penetrative convection with the Relaxed Árakawa-Schubert scheme [Moorthi and Suarez, 1992] and Richardson number-dependent fluxes in the surface layer. Recent improvements in the numerics include fourth-order advection of vorticity and all scalars and the re- 
coding of the atmospheric dynamics as a dynamical core (Suarez and Takacs, 1995). Recent improvements in the model physics include the incorporation of a new longwave parameterization [Chou and Suarez, 1996], a much more sophisticated shortwave code, and the calibration of the cloud parameterization scheme with ERBE and ISCCP data. These changes have led to an improved model climatology relative to that studied by Koster and Suarez $[1995,1996 \mathrm{a}]$.

The land surface model (LSM) used for several of the ensembles is the Mosaic LSM of Koster and Suarez [1992, 1996b], a standard soil-vegetationatmosphere-tranfer (SVAT) type LSM. This LSM, which has performed well in tests against observations [Chen et al., 1997, Wood et al., 1998], subdivides each AGCM grid square into subregions, or tiles, of relatively homogeneous vegetation type and then calculates separate one-dimensional energy and water balances over each tile, with strong stomatal control over transpiration rates.

\subsection{Simulations Performed}

The five separate ensembles of simulations performed for this study are outlined in Table 1. The first four parallel exactly the four simulations performed by $K S 95$; in the present study, however, we incorporate the model revisions outlined in section 2.1, and we tremendously increase the total length of integration. The fifth ensemble (ALOX) is of an entirely new type.

In the first four ensembles, the abilities of ocean and land surface processes 
to influence atmospheric variability are "enabled" in different combinations. To enable the ocean's influence (ensembles AO and ALO), we prescribe at the ocean boundary an interannually-varying 45-year dataset of SSTs derived from a combination of the dataset developed at the Hadley Centre (GISST2; see Rayner et al. [1996]) and a sea-ice adjusted Reynolds dataset (Reynolds and Smith, 1994, 1995]. (See Appendix A for details.) To disable this influence (ensembles $A$ and $A L$ ), we instead prescribe the climatological seasonal cycle of SSTs, which is derived directly from the 45-year dataset.

The influence of land surface processes is enabled (ensembles AL and ALO) simply by running the atmospheric GCM with the fully coupled Mosaic LSM. To disable this influence (ensembles A and AO), we replace the Mosaic LSM with a much simpler model in which the "evaporation efficiency" ( $\beta$, defined as the ratio of evaporation, $E$, to the potential evaporation, $E_{p}$ ) is prescribed at each time step rather than predicted. The prescribed climatological $\beta$ values are constructed so that ensembles $\mathrm{A}$ and $\mathrm{AO}$ reproduce the mean seasonal cycle of evaporation generated in ensemble ALO without including the short term (e.g., diurnal and synoptic-scale) or interannual variations in evaporation efficiency that result from variations in precipitation and other meteorological forcing. Since land-atmosphere feedback depends on precipitation-induced variations in evaporation efficiency, the prescription of $\beta$ is tantamount to the decoupling of atmospheric variability from variability in land surface hydrological processes. 
The construction of the $\beta$ dataset is straightforward and follows the technique used in KS95 exactly. The average value of a given tile's $\beta$ for a given month is found by averaging that month's $E$ and $E_{p}$ values separately over all years and all similations in ensemble ALO and then taking the ratio of the two averages. In other words, if we let $E^{(\mathrm{mni})}$ and $E_{p}^{(\mathrm{mni})}$ be the tile's accumulated evaporation and potential evaporation, respectively, for month $m$ of year $n$ in simulation $i$, then we compute $\beta$ for that month as:

$$
\beta^{(\mathrm{m})}=\frac{\Sigma_{n} \Sigma_{i} E^{(\mathrm{mni})}}{\Sigma_{n} \Sigma_{i} E_{p}^{(\mathrm{mni})}}
$$

Performing this calculation for each month results in a set of 12 monthly $\beta$ values for the tile, representing the "climatology" of evaporation efficiency from ensemble ALO. The simulations in ensembles $A$ and $A O$ interpolate daily values of $\beta$ from these monthly means.

We must emphasize that the prescription of $\beta$ does not imply a prescription of the evaporation rate. Evaporation can still vary on diurnal and synoptic timescales in response to corresponding variations in potential evaporation. The prescription of $\beta$ instead implies a prescription of the land surface's ability to deliver moisture to the atmosphere in response to the stated demand. In simple (though not precisely accurate) terms, prescribing $\beta$ can be thought of as prescribing soil moisture contents and canopy interception amounts.

Our final ensemble, referred to as ALOX, is similar in concept to ensemble $\mathrm{AO}$ in that SSTs vary interannually and continental $\beta$ values are prescribed 
at every time step. Ensemble ALOX, however, does not use the climatological mean $\beta$ values used in ensemble $\mathrm{AO}$; rather, it uses the interannually-varying monthly $\beta$ values generated by a single, randomly chosen member of ensemble ALO. In other words, in ensemble ALOX, the $\beta$ value applied to a tile in month $m$ of year $n$ is computed as:

$$
\beta^{(\mathrm{mn})}=\frac{E^{(\mathrm{mni})}}{E_{p}^{(\mathrm{mni})}},
$$

where $i$ represents a single representative simulation in ensemble ALO.

The prescription of $\beta$ in ensemble ALOX amounts in effect to prescribing realistic low-frequency variability in surface evaporation efficiency. The prescribed $\beta$ values have the same month-to-month variations that were attained in a simulation with interactive land surface hydrology. Only the higher frequency (intramonthly) $\beta$ variability is suppressed. As will be discussed in section 6, ensemble ALOX can be viewed as an experiment in which all surface boundary conditions relevant to seasonal-to-interannual prediction (i.e., those boundary conditions associated with significant memory) are perfectly known at all times.

Ensembles AO, ALO, and ALOX each consist of 16 members, with each member spanning the 45-year period 1949-1993. Ensembles A and AL, on the other hand, are not tied to an interannual SST dataset. These ensembles consist of only four members each, each member spanning 200 years. The only imposed difference between the members of an ensemble are the assigned initial conditions, which were derived from a multi-decade control simulation. 


\section{Overall Evaluation of Model Behavior}

\subsection{Relationship With Earlier Studies}

Because ensembles $\mathrm{A}, \mathrm{AL}, \mathrm{AO}$, and $\mathrm{ALO}$ are extended reproductions of the simulations performed by KS95, they should reproduce the main results from that earlier study. Figure 2a shows the equivalent of Figure 1a, constructed with the new simulation data. The magnitudes of the interannual variances over midlatitude land have increased slightly, reflecting the different model climatology induced by the revisions to the atmospheric GCM. The main result, however, is unchanged - the addition of interactive land surface processes contributes significantly more to the total precipitation variance than does the addition of interannually varying SSTs.

The findings from KS95, however, must be modified in the tropics. A quick comparison of Figures $1 \mathrm{~b}$ and $2 \mathrm{~b}$ shows that the imposed AGCM revisions have led to a much higher precipitation variance in each experiment. These increased variances reflect in part the higher precipitation rates generated there; for example, the mean tropical precipitation for Simulation ALO in KS95 was $1978 \mathrm{~mm}-\mathrm{y}^{-1}$, whereas the corresponding mean for ensemble ALO is $2065 \mathrm{~mm}-\mathrm{y}^{-1}$. More important than the increase in precipitation variance, however, is the decrease in the relative contribution of land surface processes to this variance. Figure $2 \mathrm{~b}$ shows that in the tropics, variable SSTs now contribute more to this variance than do interactive land surface processes. The reduction in the land surface's relative contribution (relative 
to that found in $K S 95$ ) reflects the modified model climatology. One explanation is provided in section 4.3 below, which addresses the impact of very wet conditions on the potential for land-atmosphere feedback.

\subsection{Updated Comparisons with Observations}

The KS95 study showed that the earlier version of the modeling system successfully reproduced the first order characteristics of observed precipitation means and variances. The revised modeling system shows similar success. The simulated mean annual precipitation from ensemble ALO is compared to observed values in Figure 3. The observations [Xie and Arkin, 1997] represent an optimal blend of surface raingauge measurements and satellite measurements, covering 17 years. (This observed field agrees well, by the way, with the corresponding satellite/gauge field produced as part of the Global Precipitation Climatology Project [Huffman et al., 1997]). Figure 3 shows that the model captures the main patterns and (for the most part) magnitudes of continental precipitation. Model deficiencies include an ex-

cessive tropical precipitation, particularly over the ocean but also over land, and desert regions that are too sharply defined. Rainfall in North America and Europe is somewhat overestimated.

Variances of annual precipitation, as computed from the simulated and observed data, are presented in Figure 4. A comparison of the top and middle panels shows that the model overestimates the variance significantly, particularly in the tropics. If, however, we smooth each simulated precipitation 
field with a 9-point filter prior to the variance calculation, we generate the variance field shown in the bottom panel, which is in much better agreement with the observed field. This suggests that the model's interannual variability is often excessive at the grid scale but is much more reasonable at larger spatial scales. We should also emphasize that computing grid-scale variances from the observational data is not straightforward. The apparent model error suggested by the top and middle panels of Figure 4 may be a bit overestimated for at least two reasons: (1) the sparseness of ground measurements in many tropical regions and the algorithms used to generate gridded observational data in such regions may have led to an effective "smoothing" of the observational data itself (though presumably not to the extent of a 9-point filter); and (2) the observed variances were computed from precipitation data aggregated to a $5^{\circ} \times 5^{\circ}$ grid, whereas the $\mathrm{GCM}$ variances were computed from data on a slightly finer $4^{\circ} \times 5^{\circ}$ grid.

All subsequent analyses described in this paper employ the unsmoothed precipitation data. Supplementary analyses on the smoothed data, by the way, were also performed as a check. All results regarding the nature of the land and ocean's effect on precipitation variability and predictability were found to be essentially the same when the smoothed data were used.

For the purposes of the present study, perhaps the most important aspect of precipitation variability is the strength and character of simulated land-ocean teleconnections. Figure 5 compares, for each of several represen- 
tative sites, the degree to which simulated and observed precipitation rates at the site correlate with sea surface temperatures throughout the Pacific and Atlantic Oceans. The correlation coefficients for the model are based on "ensemble mean" monthly precipitation rates, determined by averaging, for each month of each year, the precipitation rates generated by all 16 members of ensemble ALO at the site in question. The months chosen for analysis are based on an earlier study of the observational data alone by Dr. Todd Mitchell of the University of Washington, who kindly provided the precipitation observations.

Given the limited duration of the precipitation measurement record and the associated sampling errors in the observational statistics, perfect agreement between the observed and simulated correlation fields cannot be expected, even with a perfect model. (Although the measurement record overlaps well with that of the 1949-1993 SST dataset used, all of the sites studied except for Florida have a small data gap. The largest gap is for Ecuador, for which the precipitation record covers the period 1952-1987.) Nevertheless, the observed and simulated fields agree quite well in both structure and amplitude. Agreement is especially good in the Pacific; note, for example, that the Pacific correlation patterns for Ecuador and (to a lesser degree) Florida suggest that El Niño conditions in the model have a realistic impact on precipitation in these two regions. Agreement in the Atlantic is also very good, especially for precipitation in Nordeste. Of course, a close look at Fig- 
ure 5 will reveal inconsistencies between the simulated and observed fields that may or may not reflect model deficiencies - the sign of the simulated correlation in the Caribbean, for example, is wrong for Florida precipitation, and for central U.S. precipitation, the model does not reproduce observed patterns in the north Atlantic. Nevertheless, the overall agreement in the figure strongly supports the use of the model for climate variability studies.

\section{Analysis of Annual Precipitation Variance}

Whereas chaotic circulation patterns in the atmosphere impart a random component to precipitation, ocean processes (or, more specifically, spatial and temporal variations in SST) and land processes (through land-atmosphere feedback) may provide significant structure. The numerical experiments described in section 2.2 were specifically designed to isolate the contributions of atmospheric, oceanic, and land surface processes to the variability of continental precipitation. The length of the integrations (relative to those in KS95) allows new and valuable insight into the overall nature of precipitation variance.

\subsection{Effect of Variable SSTs}

We first consider the impact of adding variable SSTs to a system that is otherwise characterized by random atmospheric variations alone, with no influence from land-atmosphere feedback. (In other words, we examine how 
the precipitation timeseries generated in ensembles $\mathrm{AO}$ differ from those of ensemble A.) The inclusion of variable SSTs can affect two aspects of precipitation variability at a given point: the average amplitude of the precipitation anomalies and the time-sequencing (or "coherence") of these anomalies. These aspects are quite distinct, and as illustrated in Figure 6, a change in one need not imply a change in the other.

These two aspects of variability can be characterized with different statistical indices. First, an SST-induced increase in the amplitude of precipitation anomalies is reflected very simply by the difference in the precipitation variances generated in ensembles $\mathrm{A}$ and $\mathrm{AO}\left(\sigma_{\mathrm{A}}^{2}\right.$ and $\sigma_{\mathrm{AO}}^{2}$, respectively). Normalizing this difference by the (presumed) larger variance from ensemble $\mathrm{AO}$ gives the index $X_{O}$ :

$$
X_{O}=\frac{\sigma_{\mathrm{AO}}^{2}-\sigma_{\mathrm{A}}^{2}}{\sigma_{\mathrm{AO}}^{2}},
$$

Calculated $X_{O}$ values generally vary from 0 to 1 , though some small negative values are seen. The index can be interpreted as the fraction of the precipitation variance in ensemble $\mathrm{AO}$ that results from the addition of SST variability. The complement of this contribution (the fraction $1-X_{O}$ ) stems from chaotic atmospheric dynamics acting alone.

The second aspect reflects the ability of SSTs to guide the time-sequencing of precipitation anomalies so that the different members of ensemble $\mathrm{AO}$ will have concurrent wet years and concurrent dry years. This "coherence" can be characterized with data from ensemble $\mathrm{AO}$ alone. Let $P_{n i}^{\prime}$ represent the 
annual precipitation anomaly at a given grid cell during year $n$ of member $i$ of ensemble AO. An "ensemble mean" time series, $\hat{P}^{\prime}$, is defined as follows:

$$
\hat{P}_{n}^{\prime}=\frac{1}{I} \sum_{i=1}^{I} P_{n i}^{\prime}
$$

Thus, $\hat{P}_{n}^{\prime}$ is simply the mean precipitation anomaly for year $n$ across all $I$ ensemble members. Now let $\sigma_{P}^{2}$ represent the variance of precipitation across all $N$ years and $I$ ensemble members (i.e., across a total of $N \times I$ precipitation anomalies), and let $\sigma_{\hat{P}}^{2}$ be the variance of $\hat{P}^{\prime}$ (i.e., across $N$ ensemble mean precipitation anomalies). We define the coherence index, $\Omega_{P}(A O)$, as

$$
\Omega_{P}(A O)=\frac{I \sigma_{\hat{P}}^{2}-\sigma_{P}^{2}}{(I-1) \sigma_{P}^{2}} .
$$

Notice that if every ensemble member produced exactly the same time series of precipitation, then $\sigma_{\hat{P}}^{2}$ would attain its maximum value of $\sigma_{P}^{2}$. At the other extreme, if all values of $P_{n i}$ for each year $n$ were completely independent, then $\sigma_{\hat{P}}^{2}$ would attain its lowest (expected) value of $\sigma_{P}^{2} /$ I. The value of $\Omega_{P}$ therefore ranges (approximately) from 0 to 1 . Higher values imply a greater control of SST variations over the timing of precipitation anomalies, as in the bottom two panels on the right in Figure 6. Notice that for large enough $I, \Omega_{P}(A O)$ reduces to the simple "signal-to-total" variance ratio $\sigma_{\hat{P}}^{2} / \sigma_{P}^{2}$.

Again, $X_{O}$ and $\Omega_{P}(A O)$ characterize distinct aspects of variability. Nevertheless, an analysis of the $X_{O}$ and $\Omega_{P}(A O)$ values computed from the annual precipitation rates of ensembles $\mathrm{A}$ and $\mathrm{AO}$ shows that the two indices almost always vary together, as indicated by the scatter plot in Figure 7. Ap- 
parently, in this modeling system, an SST-induced increase in precipitation variance is almost always coupled with an increase in the coherence amongst the ensemble members. Indeed, to first order, the two indices take on the same values at a given grid cell - the points in Figure 7 are clustered around the 1:1 line.

This behavior can be conveniently explained by linearity in the modeling system. The first-order agreement between $X_{O}$ and $\Omega_{P}(A O)$ in Figure 7 can be shown to be fully consistent with the assumption that the oceanic and random atmospheric contributions to the total variance are independent, so that

$$
\sigma_{\mathrm{AO}}^{2}=\sigma_{\mathrm{SST}-\text { forced }}^{2}+\sigma_{\mathrm{random}}^{2},
$$

where $\sigma_{\text {random }}^{2}$ is the variance obtained in the absence of SST variability (e.g. in ensemble $\mathrm{A}$ ), and $\sigma_{\mathrm{SST}-\text { forced }}^{2}$ is the variance that would be obtained in the absence of chaotic atmospheric dynamics. Although the scatter in Figure 7 does support the presence of some nonlinearity associated with "Possibilities 2 and $3 "$ in Figure 6, this nonlinearity appears to be of relatively minor importance - for the most part, this is a linear system. Some of the scatter, in any case, is presumably associated with sampling error.

Through (6), we can further refine our interpretation of $X_{O}$. The numerator in (3) now represents simply the SST-forced contribution to the precipitation variance; it does not include the effects of any nonlinear atmosphere/ocean interaction. $X_{O}$ thus represents the fraction of the total precip- 
itation variance stemming from the SST forcing acting alone, while (again) $1-X_{O}$ represents the fraction stemming from random atmospheric dynamics acting alone. Given the general agreement between $X_{O}$ and $\Omega_{P}(A O)$, we will now use $X_{O}$ to characterize the ocean's contribution to precipitation variability, and we extend the linear framework to include land effects. The index $\Omega_{P}$ will be revisited, however, in our discussion of precipitation predictability in section 5 .

\subsection{Effect of Interactive Land Surface}

Intuitively, land surface processes should act to amplify precipitation anomalies - the standard paradigm of land-atmosphere feedback has a positive precipitation anomaly leading to an evaporation anomaly that in turn leads to additional precipitation (e.g., through water recycling). We introduce such effects into the simple linear framework represented by (6) via a simple amplification factor, $a_{L}$ :

$$
\sigma_{\mathrm{ALO}}^{2}=a_{L}\left(\sigma_{\mathrm{SST}-\text { forced }}^{2}+\sigma_{\mathrm{random}}^{2}\right)
$$

where $\sigma_{\mathrm{ALO}}^{2}$ is the precipitation variance from ensemble ALO. Although $a_{L}$ varies geographically, the same value is applied to both the SST-forced and the random atmospheric contributions to the variance at a given point.

Unfortunately, proving or disproving the relevance of (7) is difficult given the nature of the simulation data. An estimate of the land's amplification of 
the atmospheric contribution is afforded by ensembles A and AL:

$$
a_{L}=\frac{\sigma_{\mathrm{AL}}^{2}}{\sigma_{\mathrm{A}}^{2}},
$$

and in principle, assuming linearity, the land's amplification of the ocean's contribution can be estimated with:

$$
a_{L}=\frac{\sigma_{\mathrm{ALO}}^{2}-\sigma_{\mathrm{AL}}^{2}}{\sigma_{\mathrm{AO}}^{2}-\sigma_{\mathrm{A}}^{2}} .
$$

In these equations, $\sigma_{\mathrm{AL}}^{2}$ is the precipitation variance from ensembles $\mathrm{AL}$. Although (7) implies that $a_{L}$ from (8) and (9) should be the same, values generated with (9) are subject to considerable noise given that the denominator in the equation is often close to zero when land amplification effects are important - as will be shown below, the land's impact on the precipitation signal is generally muted in regions with a significant oceanic contribution.

We can only demonstrate an appearance of linearity indirectly. Analysis of the assumed linear system leads to the following identities:

$$
\begin{gathered}
a_{L}=\frac{\sigma_{\mathrm{AL}}^{2}}{\sigma_{\mathrm{A}}^{2}}=\frac{\sigma_{\mathrm{ALO}}^{2}}{\sigma_{\mathrm{AO}}^{2}}, \\
X_{O}=X_{O}(A L O)
\end{gathered}
$$

and

$$
\Omega_{P}(A O)=\Omega_{P}(A L O)
$$

where

$$
X_{O}(A L O)=\frac{\sigma_{\mathrm{ALO}}^{2}-\sigma_{\mathrm{AO}}^{2}}{\sigma_{\mathrm{ALO}}^{2}}
$$


and where $\Omega_{P}(A L O)$ is computed with (5), using data from ensemble ALO rather than AO. The first three plots in Figure 8 show that all three identities are supported, to first order, by the simulation results.

Although the assumption of linearity appears reasonable to first order, at least to the extent that it can be tested, we must keep in mind that some potentially important nonlinearity is known to exist. The bottom plot in Figure 8, for example, shows that the mean of the precipitation can change somewhat when interactive land surface processes are included, even though the simulations with "fixed" land surface processes used the same mean evaporation efficiencies. Differences in mean precipitation, by the way, were also found in KS95, particularly in the tropics. The changes generated in the current ensembles are smaller due to the GCM modifications described in section 2.1 .

\subsection{Oceanic, Land and Atmospheric Contributions Un- der the Linear Framework}

Under the proposed linear framework, which is supported to first order by the model diagnostics, we can characterize the precipitation variance for ensemble ALO (the experiment that includes all components of variability) as follows:

$$
\sigma_{\mathrm{ALO}}^{2}=\sigma_{\mathrm{AO}}^{2}\left[X_{O}+\left(1-X_{O}\right)\right] \frac{\sigma_{\mathrm{ALO}}^{2}}{\sigma_{\mathrm{AO}}^{2}} .
$$

This equation, of course, is a simple tautology and thus not profound in itself. The assumption of linearity, however, gives each term in the equation 
an identifiable meaning. The first term, $\sigma_{\mathrm{AO}}^{2}$ is the variance that would be achieved in the absence of land-atmosphere feedback, and $X_{O}$ and $1-X_{O}$ are the fractional contributions of oceanic and random atmospheric processes, respectively, to this variance. The term $\sigma_{\mathrm{ALO}}^{2} / \sigma_{\mathrm{AO}}^{2}$ is the amplification of this variance due to interactive land surface processes.

Figure 9 shows a plot of all four terms and thus provides, to the extent that the model behaves linearly, a full characterization of oceanic, atmospheric, and land contributions to precipitation variance. As expected, the variance in the absence of land-atmosphere feedback (top left plot) is generally smaller than that of the total variance (Figure 4) but nevertheless has the same overall structure. Land-atmosphere feedback (bottom right plot) increases this variance everywhere but in deserts, high latitudes, and the very wet areas of the tropics. The oceanic contribution to the variance (top right plot) is high in the tropics and in parts of the Sahara but remains below $30 \%$ throughout midlatitudes - there, the precipitation variance is controlled mostly by chaotic atmospheric dynamics. This tropical/extratropical contrast in the ocean's impact, by the way, is not unique to this model; it has been seen in various forms in several other studies as well [e.g., Kumar and Hoerling, 1995; Trenberth et al., 1998; Shukla, 1998].

The breakdown in Figure 9 allows us to address the hypothesis from KS95 discussed in the introduction, namely that SST anomalies can be strongly correlated in time with precipitation anomalies even while land-atmosphere 
feedback controls the amplitude of the latter. As discussed above, the ocean's impact on the time-sequencing of anomalies is characterized by the index $\Omega_{P}(A O)$ or $\Omega_{P}(A L O)$, which, in a linear system, is equivalent to $X_{O}$. A study of Figure 9 shows that the areas for which $X_{O}$ (top right plot) is large generally coincide with areas for which the land amplification factor $\left(a_{L}\right.$, bottom right plot) is small, implying that the land and ocean generally affect precipitation variance in different regions. This is more directly emphasized in Figure 10, which shows a scatterplot of $\Omega_{P}(\mathrm{ALO})$ versus $a_{L}$ - the land surface's amplification of the precipitation signal can be high for smaller values of $\Omega_{P}$ but is relatively suppressed in regions of high $\Omega_{P}$. We thus address the hypothesis in this way: although the hypothesis is fully consistent with the linear framework, and although we can find grid cells for which both $\Omega_{P}$ and the land amplification factor are significant, the model does not generally show a strong oceanic control over the time-sequencing of anomalies combined with a large land-induced amplification of these anomalies. Landatmosphere feedback is most important outside of the areas most influenced by variable SSTs.

A second hypothesis, first introduced by Koster and Suarez [1999], can also be addressed with the simulation results and the linear framework. Koster and Suarez [1999] show that the variance of evaporation in a given continental region is strongly related to the variance of precipitation and 
Budyko's $[1958,1974]$ index of dryness, defined as

$$
\phi=\frac{R_{A}}{P_{A} L},
$$

where $R_{A}$ is the annual mean net radiation, $P_{A}$ is the annual mean precipitation, and $L$ is the latent heat of vaporization, used to make $\phi$ dimensionless. Evaporation variability (normalized by precipitation variability) was essentially shown to decrease monotonically to zero as $\phi$ decreases to zero (e.g., as conditions get wetter for a given net radiation). Because land-atmosphere feedback relies on evaporation variability (or, more specifically, on the response of evaporation anomalies to precipitation anomalies), we can hypothesize that this feedback should become more suppressed as $\phi$ approaches zero - the land's amplification of precipitation anomalies (as characterized by $a_{L}$ ) should be smaller in regions that are more energy-limited.

This hypothesis is clearly supported by the model results. Figure 11a shows the global distribution of dryness index, $\phi$, computed with (15) using climatological annual mean fluxes from ensemble ALO. The expected high $\phi$ values in deserts are clearly seen, as are the expected low values in the wet tropics and at polar latitudes. A quick comparison between this distribution and the $a_{L}$ distribution from Figure 9 shows that the regions of low $\phi$ in northern South America and other tropical continents coincide exactly with regions of low $a_{L}$. Apparently, in these regions, evaporation is not waterlimited and thus cannot respond well to precipitation anomalies, and this weakens the basic mechanism for feedback. This is shown more clearly in the 
scatter plot in Figure 11b. Although the relationship between the two indices is not perfect, the plot shows a clear reduction of $a_{L}$ for values of $\phi$ below 1 , suggesting that the relative availability of energy and water (as characterized by $\phi$ ) does indeed exert an important control over the feedback.

This provides one explanation, by the way, for why the results for the new AGCM differ from those of KS95 in the tropics. (See the discussion in section 3.1 regarding the comparison of Figures 1 and 2.) The revised AGCM produces more precipitation in the tropics in all ensembles, reducing tropical $\phi$ values and thereby weakening land-atmosphere feedback. As a result, the relative contribution of land surface processes to tropical precipitation variability is diminished in the revised model.

The apparent relationship between $\phi$ and land-atmosphere feedback sheds some light on the earlier result, namely that the ocean and land processes have markedly different regional domains of influence. First, we note that the $\phi$ distribution in Figure 11 is almost the same as that computed from ensemble AL (not shown), implying that ocean variability has little impact on $\phi$ and thus on land-atmosphere feedback. Second, we note that the distribution of $X_{O}$ in Figure 9 is similar to the distribution (not shown) of $\left(\sigma_{\mathrm{ALO}}^{2}-\sigma_{\mathrm{AL}}^{2}\right) / \sigma_{\mathrm{ALO}}^{2}$, implying that land-atmosphere feedback has little impact on the ocean's domain of influence. Taken together, these statements suggest that the complementary nature of the regions influenced by land and ocean processes is, on the whole, fortuitous rather than the result of some 
exclusion mechanism. Ocean processes happen to be most important in wet parts of the tropics, where $\phi$ happens to be low enough to prevent significant land-atmosphere feedback.

We chose to focus on annual precipitation totals in the analysis above in order to illustrate the gross influences of oceanic, atmospheric, and land processes on precipitation variance. These gross influences are essentially shown in Figure 9. Before closing this section, we note that an analysis of seasonal totals is, of course, also possible. When totals for boreal summer (JJA) are examined instead, the apparent nonlinearity does increase somewhat, but the linear framework is still found to be relevant, at least to first order. A plot analogous to Figure 9, using data for JJA, shows a similar tropical/extratropical contrast in the ocean's influence but (as expected from KS95) greatly increased values of $a_{L}$ in northern hemisphere midlatitudes.

\section{Analysis of Precipitation Predictability}

The present section focuses on the seasonal-to-interannual predictability of precipitation in a forecasting system and how it relates to knowledge of surface boundary conditions. The model simulations discussed above and the coherence index, $\Omega_{P}$, fit neatly into this analysis. 


\subsection{Upper Limits of Predictability}

Given the chaotic nature of the atmosphere and the short residence times associated with atmospheric transport, all hope for seasonal-to-interannual prediction lies in the accurate prediction of surface boundary conditions and in the accurate simulation of atmospheric response to the predicted boundary conditions. The pre-eminent boundary condition considered in predictability studies has been sea surface temperature [e.g., Goswami and Shukla, 1991; Graham et al., 1994; Liang et al., 1997]. SST anomalies are associated with the relatively long memory of the upper ocean, and they exhibit changes that can be predicted with coupled ocean-atmosphere models at least six months in advance, or even longer if the ocean subsurface is initialized through the assimilation of ocean observations [e.g., Zebiak and Cane, 1987; Barnett et al., 1993; Ji and Leetmaa, 1997; Rosati et al., 1997].

Even if SSTs could be predicted perfectly, however, chaotic atmospheric dynamics would impose serious limits to precipitation predictability. These limits are conveniently and precisely measured with $\Omega_{P}$ from (5). Again, $\Omega_{P}$, as computed from ensembles $\mathrm{AO}$ or ALO, quantifies the robustness of the precipitation response to a prescribed time-varying SST field. If $\Omega_{P}$ for a region is near zero, then different simulations of an ensemble produce disparate precipitation responses to the same SST field. As a result, regardless of the accuracy of the SST forecasts, precipitation predictions in the region would generally have a wide spread and would not be particularly useful. 
A global field of $\Omega_{P}$ can therefore be interpreted as field of "maximum potential prediction skill" in a modeling system that relies solely on SST forecasts. Figure 12 shows global fields of $\Omega_{P}$ from ensemble ALO for two seasons, boreal summer (JJA) and boreal winter (DJF). The figure suggests that our own modeling system could produce useful predictions throughout much of the tropics (to the extent, of course, that SST forecasts and simulated teleconnections between land and ocean are accurate). The modeling system, however, would necessarily be ineffective in midlatitudes and high latitudes. We note in passing that the processing of simulated temperature fields in an analogous way reveals a similar tropical/extratropical contrast in temperature predictability, though this predictability is higher than that for precipitation throughout the globe. We also note again that the tropical/extropical contrast seen in Figure 12 has been seen in several other modeling systems.

For effective prediction outside of the tropics, we must be able to forecast a time-varying boundary condition other than sea surface temperature. The obvious candidate for this boundary condition is the land surface moisture state. Surface moisture reservoirs (particularly snow and soil moisture reservoirs) are associated with a memory that may span weeks to months, and thus a proper initialization of these reservoirs automatically implies some degree of skill in forecasting their state. Numerous modeling studies [e.g., Shukla and Mintz, 1982; Oglesby and Erickson, 1989; Betts et al., 1994; Koster and 
Suarez, 1995, 1996] and some indirect observational studies [e.g., Salati et al., 1979; Brubaker et al., 1993] suggest that continental precipitation rates respond to variations in surface moisture through its effect on evaporation, the implication being that surface moisture prediction may, to a degree, be translated into precipitation prediction.

To determine the extent to which knowledge of land surface moisture state leads to improved precipitation prediction, we examine ensemble ALOX. In this ensemble (see section 2.2), the low frequency variability of the evaporation efficiency $\beta$ (the ratio of evaporation to the potential evaporation) is prescribed $-\beta$ values vary monthly and interannually in exactly the same way for all ensemble members. Because interannually-varying SSTs are also prescribed, ensemble ALOX prescribes the critical surface boundary conditions - those boundary conditions that would be expected to retain significant memory - over the entire Earth surface. Considered in terms of the precipitation forecasting problem, ensemble ALOX represents the ideal situation in which the critical surface boundary conditions can be predicted perfectly. Variations in precipitation generation amongst the ensemble members essentially reflect only the chaotic nature of the atmospheric circulation.

Figure 13 shows how $\Omega_{P}$, as computed from ensemble ALOX, varies globally for both summer (JJA) and winter (DJF) conditions. By comparing these fields to those in Figure 12 via the accompanying difference maps, we find that perfect knowledge of land surface moisture state leads to highly 
significant increases in predictability for JJA in central North America, in southern Europe, in a band that stretches across Asia, and throughout the tropics. For DJF, increases are seen mainly in the tropics and in southern hemisphere midlatitudes. The land surface is clearly more coupled to the atmosphere during summer, when evaporation is highest.

The top panels of Figure 13 provide, in fact, the absolute upper limits of predictability in the modeling system. This suggests an important caveat. Higher values of $\Omega_{P}$ in the figure may have limited practical meaning -- actual predictability may be lower than that implied by $\Omega_{P}$ for at least two reasons. First, in ensemble ALOX, we asssume that land surface moisture state can be predicted perfectly; we do not allow it to be redirected by the chaotic element of local weather patterns. In an operational system, initialization of soil moisture does provide some predictive skill, but our overall ability to predict land surface state necessarily decays with time. Second, the interpolation of the prescribed $\beta$ values in the experiment from independently derived monthly-averaged values implies a lack of high-frequency variability in $\beta$. In nature, and in a simulation with an interactive LSM, $\beta$ can vary on the hourly timescale due to variations in solar radiation, temperature, and canopy interception reservoir content. The consideration in ensemble ALOX of only low frequency variability in $\beta$ precludes the amplification of high-frequency atmospheric noise by land surface processes [Scott et al., 1995]. 
In other words, actual predictability may or may not be high where $\Omega_{P}$ is high in Figure 13. Much of the value of the figure lies instead in identifying those regions for which $\Omega_{P}$ is low. In these regions, atmospheric variability by itself overwhelms any memory associated with SSTs and land surface moisture. In general, regardless of the skill attained in forecasting surface boundary conditions, the coupled system cannot provide useful seasonal-tointerannual predictions in these regions, since the precipitation there is not strongly tied to the boundary conditions.

Thus, predictability in many extratropical regions is fundamentally limited. Still, we must allow for the possibility that certain extremes in the surface boundary conditions may lead to a predictable precipitation response in regions of low $\Omega_{P}$ - occasionally, under certain conditions, a useful prediction there might be made. Predictability might increase significantly, for example, during ENSO events, though a preliminary analysis of the data does not bear this out. Detailed analysis of contemporaneous precipitation and surface data is needed to ferret out any helpful relationships.

\subsection{An Apparent Connection Between Predictability and Relative Humidity}

Why does the land surface contribute more to predictability in some regions than in others, as shown in the lower panels of Figure 13? We can intuitively cite at least two requirements for a strong land surface contribution: (1) variations in the evaporation must be large enough to affect the overlying 
atmosphere, and (2) the evaporation itself must have a robust response to the land surface moisture state. In this exercise, the second requirement means that the timeseries of evaporation rates generated by the different members of ensemble ALOX must be similar, given that each uses the same timeseries of evaporation efficiency. We could not, after all, expect a robust precipitation response from dissimilar evaporation forcing. Following the arguments in section 4.1, the second requirement implies that $\Omega_{E}$ needs to be close to 1 , where

$$
\Omega_{E}=\frac{I \sigma_{\grave{E}}^{2}-\sigma_{E}^{2}}{(I-1) \sigma_{E}^{2}},
$$

and where $\sigma_{E}^{2}$ and $\sigma_{\overparen{E}}^{2}$ are the total evaporation variance and the evaporation variance for the ensemble mean, respectively, computed from ensemble ALOX.

Figure 14 shows that the extent to which both criteria are met is related to the local near-surface relative humidity, $h$. The top panel shows that the mean evaporation tends to be small in regions of low $h$ (deserts). Thus, the variations in evaporation that occur in these regions should also generally be small. Note that we are not implying a causal relationship between low $h$ and low evaporation. The low evaporation rates seen at high values of $h$, by the way, correspond largely to cold, high latitude regions.

The bottom panel of Figure 14 shows that $\Omega_{E}$ is very close to one except at high values of $h$, where it drops precipitously to near zero. The low values of $\Omega_{E}$ at high $h$ may reflect unpredictable variations in potential evapora- 
tion, $E_{p}-$ if $E_{p}$ is strongly affected by chaotic atmospheric dynamics (e.g., by chaotic variations in cloud cover), then evaporation rates will remain unpredictable even if evaporation efficiencies (i.e., surface moisture states) are fully known. Alternatively, the low values may reflect a strong evaporation feedback on surface temperature, by which low values of $E / E_{p}$ are strongly correlated with high values of $E_{p}$. When this correlation is high, the interannual variability of evaporation is suppressed, which reduces $\Omega_{E}$. Both situations (unpredictable $E_{p}$ and high temperature feedback) can be shown to be consistent with high relative humidity, for which the contribution of the humidity deficit to the potential evaporation [Penman, 1948], a stabilizing influence, is small.

In light of the two criteria for a significant land surface contribution to predictability, the top panel of Figure 14 suggests that the contribution should usually be small in dry regions, and the bottom panel suggests that it should usually be small in humid regions. Figure 14 therefore suggests that knowledge of the land surface state should be most important in regions of intermediate relative humidity. This is, in fact, precisely what we find. Figure 15 shows the global distribution of estimated relative humidity at the top of the surface boundary layer for both JJA and DJF. Overlain on the plots are small dots indicating where the differences shown in the bottom panels of Figure 13 (i.e., where the increases in predictability due to perfect knowledge of the land surface state) exceed 0.3. The significant land surface contribu- 
tions are, in general, clearly found in the transition zones between very dry and very humid environments. This is particularly true in the tropics and summer extratropics of each plot, since in summer, evaporation rates for a given relative humidity are significantly higher.

(A look at Figure 11, by the way, might suggest that increases in predictability due to knowledge of land surface state could also be related to the dryness index, $\phi$, computed from the seasonal mean precipitation and radiation values. This relationship, however, turns out to be weaker.)

Thus, based on the model's distribution of relative humidity, a reflection of its overall climatology, we can predict a priori where knowledge of the land surface's state will aid in precipitation prediction. This has important implications for soil moisture data assimilation in the context of seasonal-to-interannual forecasting. Such data assimilation is often touted as a potentially effective means of increasing prediction skill [Houser et al., 1998]. These claims may indeed be justified, but perhaps mainly in regions of intermediate relative humidity. Perhaps these are the regions over which soil moisture data assimilation techniques should be developed.

\section{Summary}

The numerical integration of a global coupled land-atmosphere system over several thousand years provides the meteorological statistics needed for many climate variability studies. In this paper, we use the data to address the 
nature of precipitation variance and predictability on seasonal-to-interannual timescales.

The first part of our study focuses on the relative contributions of oceanic, atmospheric, and land surface processes to the variance of annual precipitation. The model diagnostics suggest that the problem can be analyzed, to first order, in terms of a simple linear system in which land-atmosphere feedback acts to amplify separate and independent contributions from the ocean and atmosphere. Figure 9 shows the breakdown of contributions based on this linear framework. Variable SSTs contribute the most to precipitation variance in the tropics, whereas chaotic atmospheric dynamics contribute the most in the extratropics. The land amplifies the precipitation signal in various places across the globe but particularly outside of the wet parts of the tropics.

In an earlier study [Koster and Suarez, 1995], we speculated that SSTs can control the timing of precipitation anomalies even while land surface processes control their magnitude. The present variance analysis suggests that although this can and does happen in certain grid cells, land and ocean processes generally have different domains of influence - amplification via landatmosphere feedback is generally (and fortuitously) not large when the SSTforced part of the precipitation signal dominates over the randomly forced part. The model results do provide strong support for a hypothesis proposed in Koster and Suarez [1999], namely that the potential for land-atmosphere 
feedback is severely weakened in regions having a low climatological index of dryness, as defined by Budyko $[1958,1974]$.

The second part of our study focuses on the predictability of precipitation at seasonal-to-interannual timescales. In particular, we quantify the extent to which perfect knowledge of SSTs and land surface moisture state contributes to the robustness of the precipitation signal generated by different members of a given ensemble. This is equivalent to establishing upper bounds on the seasonal-to-interannual predictability of precipitation over continents.

In our experiments, the land surface moisture state is characterized by $\beta$, which essentially represents the impact of all surface reservoir moisture states (e.g., soil moisture content and snow amount) on evaporation. Knowledge of $\beta$ contributes significantly to predictability in many tropical and midlatitude regions, as indicated in the bottom panels of Figure 13. These regions tend to be located in the transition zones between dry and humid areas, which has important implications for soil moisture initialization strategies in forecast systems - such initialization may have limited benefit outside of these transition zones. In regions for which $\Omega_{P}$ from ensemble ALOX (see the top panels of Figure 13) is close to zero, the coupled modeling system will be severely limited in its ability to generate useful precipitation forecasts.

The extent to which all of these results apply to precipitation variability in the real world, of course, depends on the accuracy of the simulated variability, teleconnections, and feedback processes. Various comparisons with 
observations show that the model does behave reasonably, though not perfectly. The results presented, in any case, do have direct bearing on the understanding of precipitation behavior in the coupled system and thus on the potential for using this particular system to make long-term forecasts. Other modeling groups might consider a similar analysis to improve understanding of their own systems.

The results above, by the way, suggest some obvious additional analyses. First, nonlinearity in the interactions between oceanic, atmospheric, and land surface processes was small in general and thus ignored in the variance analysis. Nonlinearity may manifest itself in important ways in some regions, however, and this behavior may be worthy of study. Second, the predictability result above is conditioned on perfect knowledge of the land surface state. In both the real world and the modeling system, the "memory" associated with continental moisture - and thus our ability to forecast land surface moisture state - is limited. The nature of this limitation and its effect on our ability to forecast precipitation are important problems yet to be solved.

Acknowledgments. This work was supported by funding from the Earth Science Enterprise, NASA Headquarters. Dr. Todd Mitchell supplied the precipitation observations used to generate Figure 5, and Larry Marx provided critical SST data. 


\section{Appendix A: Construction of the SST Dataset}

The $4^{\circ} \times 5^{\circ}$ climatological SSTs (i.e., the mean seasonal cycle of the SSTs) used in these experiments are simply aggregates of the $1^{\circ} \times 1^{\circ}$ optimum interpolation SST (OISST) climatology of Reynolds and Smith (1995). However, a multi-step process is required to produce the interannually-varying $4^{\circ} \times 5^{\circ}$ monthly mean SSTs for the January 1949 to December 1994 period. $1^{\circ} \times 1^{\circ}$ monthly mean GISST2.2 data [Rayner et al., 1996] from 1/49-4/82 and a sea ice adjusted version of the $1^{\circ} \times 1^{\circ}$ degree monthly mean OISST data [Reynolds and Smith, 1994] from 11/81-12/94 are used in this process. Note that the adjustment to the monthly mean OISST data involves computing daily ice fractions for each month from linearly interpolated NCEP OMB weekly ice fractions and setting the OISST equal to $-1.8 \mathrm{C}$ whenever ice is present at a grid point for more than $50 \%$ of the month [Larry Marx, pers. com.].

Initially, monthly SST anomaly fields are computed for both the $1^{\circ} \times 1^{\circ}$ GISST2.2 and OISST data by subtracting each dataset's own mean seasonal cycle from its monthly mean SSTs. The anomaly data sets are then merged together using weighted averages to smooth the transition from GISST2.2 to OISST anomalies during the 6 months where the two data sets overlap $(11 / 81-4 / 82)$ :

Nov 1981: ANOM $=[$ GISST ANOM $\times 6 .+$ OISST ANOM $\times 1] / 7$.

Dec 1981: $A N O M=[$ GISST ANOM $\times 5 .+$ OISST ANOM $\times 2] / 7$. 
Jan 1982: ANOM $=[$ GISST ANOM $\times 4 .+$ OISST ANOM $\times 3] / 7$.

Feb 1982: $A N O M=[$ GISST ANOM $\times 3 .+$ OISST ANOM $\times 4] /$.7 .

Mar 1982: $\mathrm{ANOM}=[$ GISST ANOM $\times 2 .+$ OISST ANOM $\times 5] /$.7 .

Apr 1982: $\mathrm{ANOM}=[$ GISST ANOM $\times 1 .+$ OISST ANOM $\times 6] /$.7 .

The single merged dataset of SST anomalies is then added to the OISST climatology to produce the interannually-varying SST fields. SSTs are limited to a minimum of $-1.8 \mathrm{C}$ to correct for anomalously cold SSTs that appear when the GISST2.2 anomalies are added to the OISST climatology. Finally, the SST data are aggregated to the $4^{\circ} \times 5^{\circ}$ model grid.

The GISST $2.21^{\circ} \times 1^{\circ}$ ice fraction climatology and the $1 / 49-12 / 94$ monthly $1^{\circ} \times 1^{\circ}$ ice fractions from this dataset are used in the production of the $4^{\circ} \times 5^{\circ}$ climatological and monthly mean ice fraction data sets. The GISST $2.21^{\circ} \times 1^{\circ}$ ice fraction data are adjusted so that the ice fraction equals zero when the SST is $3 \mathrm{C}$ or higher, and it is set to (3C-SST) $\times$ (ice fraction) when when the SST is between $2 \mathrm{C}$ and $3 \mathrm{C}$. These data are then aggregated to the $4^{\circ} \times 5^{\circ}$ model grid.

Climatological and monthly mean $4^{\circ} \times 5^{\circ}$ sea ice temperatures (SIT) are produced based on a $4^{\circ} \times 5^{\circ}$ SIT and ice fraction climatology created by Dr. Chang-hoi Ho. Production of the SIT dataset requires setting the SIT equal to:

- the $4^{\circ} \times 5^{\circ} \mathrm{SST}$ if the $4^{\circ} \times 5^{\circ}$ ice fraction is 0 (SIT not used in this case) 
$--1.8 \mathrm{C}$ if the $4^{\circ} \times 5^{\circ}$ ice fraction exceeds 0 and Ho's ice fraction $=0$

- Ho's ice temperature if both the $4^{\circ} \times 5^{\circ}$ ice fraction and Ho's ice fraction exceed 0 .

\section{References}

Alekseev, V. and 33 others, 1996: Cloud feedback in atmospheric general circulation models, an update, J. Geophys. Res., 101, 12791-12794.

Arkin, P. and P. Xie, 1994: The Global Precipitation Climatology Project: First Algorithm Intercomparison Project, Bull. Amer. Meteor. Soc., 75, 401-419.

Barnett, T.P., M. Latif, N. Graham, M. Flugel, S. Pazan, and W. White, 1993: ENSO and ENSO-related predictability, Part I, Prediction of Equatorial Pacific Sea Surface Temperature with a hybrid coupled oceanatmosphere model, J. Clim., 6, 1545-1566.

Bates, J. J., and D. L. Jackson, 1997: A comparison of water vapor observations with AMIP I simulations, J. Geophys. Res., 102, 21837-21852.

Betts, A.K., J.H. Ball, A.C.M. Beljaars, M.J. Miller, and P. Viterbo, 1994: Coupling between land-surface, boundary-layer parameterizations and rainfall on local and regional scales: Lessons from the wet summer of 1993, in Fifth Conference on Global Change Studies, 74th Annual Meeting, American Meteorological Society, Boston, Mass.

Boyle, J. S., 1998a: Evaluation of the annual cycle of precipitation over the United States in GCMs, AMIP simulations, J. Climate, 11, 1041-1055.

Boyle, J. S., 1998b: Intercomparison of interannual variability of the global 200-hPa circulation for AMIP simulations, J. Climate, 11, 2505-10552529.

Brubaker, K.L., D. Entekhabi, and P.S. Eagleson, 1993: Estimation of continental precipitation recycling, J. Clim., 6, 1077-1089.

Budyko, M. I., 1958: The Heat Balance of the Earth's Surface, translated by Nina A. Stepanova, U. S. Dept. of Commerce, Washington, D. C., 259 p.

Budyko, M. I., 1974: Climate and Life, Academic Press, New York, 508 p.

Cess, R. D. and 31 others, 1990: Intercomparison and interpretation of climate feedback processes in 19 atmospheric general circulation models, J. Geophys. Res., 95, 16601-16615. 
Chen, T.H. and 42 others, 1997: Cabauw experimental results from the Project for Intercomparison of Landsurface Parameterization Schemes (PILPS), J. Climate, 10, 1194-1215.

Chou, M.-D. and M. Suarez, 1994: An efficient thermal infrared radiation parameterization for use in general circulation models, NASA Technical Memorandum 104606, Vol. 3.

Davies, J. R., D. P. Rowell, and C. K. Folland, 1997: North Atlantic and European seasonal predictability using an ensemble of multidecadal atmospheric GCM simulations, Int. J. Clim., 17, 1263-1284.

Delworth, T.L., and S. Manabe, 1988: The influence of potential evaporation on the variabilities of simulated soil wetness and climate, J. Clim., 1, 523-547.

Delworth, T.L., and S. Manabe, 1989: The influence of soil wetness on nearsurface atmospheric variability, J. Clim., 2, 1447-1462.

Gates, W.L., 1992: AMIP, The atmospheric model intercomparison project, Bull. Am. Met. Soc., 73, 1962-1970.

Goswami, B.N. and J. Shukla, 1991: Predictability of a coupled oceanatmosphere model, J. Climate, 4, 3-22.

Graham, N.E., T.P. Barnett, R. Wilde, M. Ponater, and S. Schubert, 1994: On the roles of tropical and midlatitude SSTs in forcing interannual to interdecadal variability in the Winter Northern Hemisphere circulation, J. Clim., 7, 1416-1441.

Houser, P. R., W. J. Shuttleworth, J. S. Famiglietti, H. V. Gupta, K. H. Syed, and D. C. Goodrich, 1998: Integration of soil moisture remote sensing and hydrologic modeling using data assimilation, Water Resources Research, 34, 3405-3420.

Huffman, G. J., R. F. Adler, P. Arkin, A. Chang, R. Ferraro, A. Gruber, J. Janowiak, A. McNab, B. Rudolf, and U. Schneider, 1997: The Global Precipitation Climatology Project (GPCP) combined precipitation data sets, Bull. Am. Met. Soc., 78, 5-20.

Ji, M., and A. Leetmaa, 1997: Impact of data assimilation on ocean initialization and El Nino prediction, Mon. Wea. Rev., 125, 742-753.

Karl, T. R., V. E. Derr, D. R. Easterling, C. K. Folland, D. J. Hofmann, S. Levitus, N. Nicholls, D. E. Parker, and G. W. Withee, 1995: Critical issues for long-term climate monitoring, Climatic Change, 31, 185-221.

Koster, R. D. and M. J. Suarez, 1992: Modeling the land surface boundary in climate models as a composite of independent vegetation stands, $J$. Geophys. Res., 97, 2697-2715.

Koster, R. D. and M. J. Suarez, 1995: The relative contributions of land and ocean processes to precipitation variability, J. Geophys. Res., 100, 13775-13790. 
Koster, R. D. and M. J. Suarez, 1996a: The influence of land surface moisture retention on precipitation statistics, J. Climate, 9, 2551-2567.

Koster, R. and M. Suarez, 1996b: Energy and Water Balance Calculations in the Mosaic LSM, NASA Tech. Memo. 104606, Vol. 9.

Koster, R. D., and M. J. Suarez, 1999: A simple framework for examining the interannual variability of land surface moisture fluxes, Journal of Climate, in press.

Kumar, A. and M. P. Hoerling, 1995: Prospects and limitations of seasonal atmospheric GCM predictions, Bull. Amer. Met. Soc., 76, 335-345.

Lau, K.-M., and W. Bua, 1998: Mechanisms of monsoon-Southern Oscillation coupling, insights from GCM experiments, Clim. Dyn., 14, 759-779.

Liang, X.-Z., K.R. Sperber, W.-C. Wang, and A.N. Samel, 1997: Predictability of SST forced climate signals in two atmospheric general circulation models, Climate Dynamics, 13, 391-415.

Manabe, S. and D. G. Hahn, 1981: Simulation of atmospheric variability, Mon. Weath. Rev., 109, 2260-2286.

Moorthi, S., and M. J. Suarez, 1992: Relaxed Arakawa-Schubert, a parameterization of moist convection for general circulation models, Mon. Wea. Rev., 120, 978-1002.

Oglesby, R.J., and D.J. Erickson III, 1989: Soil moisture and the persistence of North American drought, J. Clim., 2, 1362-1380.

Penman, H. L., 1948: Natural evaporation from open water, bare soil, and grass, Proc. Roy. Soc. London (A), 193, 120-145.

Rayner, N.A., E.B. Horton, D.E. Parker, C.K. Folland, and R.B. Hackett, 1996: Version 2.2 of the Global sea-Ice and Sea Surface Temperature data set, 1931-994. Climate Research Technical Note CRTN 74, Hadley Centre, Met. Office, Bracknell, U.K.

Reynolds, R. W. and T. M. Smith, 1994: Improved global sea surface temperature analyses using optimum interpolation. J. Climate, 7, 929-948.

Reynolds, R. W. and T. M. Smith, 1995: A high resolution global sea surface temperature climatology. J. Climate, 8, 1571-1583.

Robock, A., C. A. Schlosser, K. Y. Vinnikov, N. A. Speranskaya, J. K. Entin, and S. Qiu, 1998: Evaluation of the AMIP soil moisture simulations, Glob. and Planet. Change, 19, 181-208.

Rosati, A., K. Miyakoda, and R. Gudgel, 1997: The impact of ocean initial conditions on ENSO forecasting with a coupled model, Mon. Wea. Rev., 125, 754-772.

Salati, E., A. Dall'Olio, E. Matsui, and J.R. Gat, 1979: Recycling of water 
in the Amazon Basin: An isotopic study, Water Resour. Res., 15, 12501258.

Scott, R., R. D. Koster, D. Entekhabi, and M. J. Suarez, 1995: Effect of a canopy interception reservoir on hydrological persistence in a general circulation model, J. Climate, 8, 1917-1922.

Shukla, J., 1998: Predictability in the midst of chaos: A scientific basis for climate forecasting, Science, 282, 728-731.

Shukla, J., and Y. Mintz, 1982: Influence of land-surface evapotranspiration on the earth's climate, Science, 215, 1498-1501.

Strauss, D. M., and J. Shukla, 1997: Variations of midlatitude transient dynamics associated with ENSO, J. Atm. Sci., 54, 777-790.

Suarez M. J., and L. L. Takacs, 1995: Documentation of the ARIES/GEOS Dynamical Core: Version 2, NASA Technical Memorandum 104606, Vol. 5.

Trenberth, K. E., G. W. Branstator, D. Karoly, A. Kumar, N. C. Lau, and C. Ropelewski, 1998: Progress during TOGA in understanding and modeling global teleconnections associated with tropical sea surface temperatures, J. Geophys. Res., 103, 14291-14324.

Willmott, C.J., S.M. Robeson, and J.J. Feddema, 1994: Estimating continental and terrestrial precipitation averages from rain-gauge networks, Int. J. Climatol., 14, 403-414.

Wood, E.F., and 28 others, 1998: The project for the intercomparison of landsurface parameterization schemes (PILPS) phase 2(c) Red Arkansas river basin experiment, 1, Experiment description and summary intercomparisons, J. Global and Planetary Change, 19, 115-135.

Xie, P. and P. Arkin, 1997: Global precipitation, a 17-Year monthly analysis based on gauge observations, satellite estimates and numerical model outputs, Bull. Am. Met. Soc., 78, 2539-2558.

Zebiak, S. and M.A. Cane, 1987: A model El Nino-Southern Oscillation, Mon. Wea. Rev., 115, 2262-2278. 


\section{Figure Captions}

Fig. 1 Histogram showing, for each simulation in the KS95 study, the variance of annual precipitation averaged over (a) northern hemisphere midlatitude land $\left(30^{\circ} \mathrm{N}-50^{\circ} \mathrm{N}\right)$ and (b) tropical land $\left(10^{\circ} \mathrm{S}-10^{\circ} \mathrm{N}\right)$.

Fig. 2 Histogram showing, for each of the ensembles examined in the current study, the variance of annual precipitation averaged over (a) northern hemisphere midlatitude land $\left(30^{\circ} \mathrm{N}-50^{\circ} \mathrm{N}\right)$ and (b) tropical land $\left(10^{\circ} \mathrm{S}-\right.$ $\left.10^{\circ} \mathrm{N}\right)$.

Fig. 3 Top: Annual mean precipitation ( $\mathrm{mm} /$ day) from the CPC Merged Analysis of Precipitation (CMAP, satellites and gauges only) [Xie and Arkin, 1997]. Bottom: Annual mean precipitation (mm/day), as computed from the 720 years of data from ensemble ALO.

Fig. 4 Top: Variance of annual precipitation $\left(\mathrm{mm}^{2} /\right.$ day $\left.^{2}\right)$ calculated from the CPC Merged Analysis of Precipitation (CMAP) [Xie and Arkin, 1997]. Middle: Variance of annual precipitation $\left(\mathrm{mm}^{2} / \mathrm{day}^{2}\right)$, as computed from the 720 years of data from ensemble ALO. Bottom: Variance of annual precipitation $\left(\mathrm{mm}^{2} / \mathrm{day}^{2}\right)$ from ensemble ALO, computed after first smoothing each annual field with a 9-point filter.

Fig. 5 Simulated and observed correlations, $r$, between SST anomlies (averaged over the months indicated) and concurrent precipitation anomalies at four representative sites: (a) Ecuador; (b) Florida (including additional gulf stations for the observational analysis); (c) northeast Brazil; and (d) the central United States. The precipitation data used to generate the observed correlations are courtesy of Dr. Todd Mitchell of the University of Washington.

Fig. 6 Illustration of the ways by which the inclusion of time-varying sea surface temperatures can affect precipitation variability at a given point. The timeseries shown are idealized; they do not represent actual data from the ensembles.

Fig. 7 Scatter plot of amplitude index $\left(X_{O}\right)$ versus coherence index $\left(\Omega_{P}(A O)\right)$ as diagnosed from ensembles $\mathrm{A}$ and $\mathrm{AO}$. Each point in the plot represents a land surface grid cell with an average precipitation exceeding $0.1 \mathrm{~mm} /$ day.

Fig. 8 Top left: Test of linearity through a comparison of $\frac{\sigma_{\mathrm{AL}}^{2}}{\sigma_{\mathrm{A}}^{2}}$ with $\frac{\sigma_{\mathrm{ALO}}^{2}}{\sigma_{\mathrm{AO}}^{2}}$, calculated with annual means. Top right: Test of linearity through a comparison of $X_{O}$ from (3) with $X_{O}$ from (13), calculated with annual means. Bottom left: Test of linearity through a comparison of $\Omega_{P}(A L)$ 
with $\Omega_{P}(A L O)$, calculated with annual means. Bottom right: Test of linearity through a comparison of mean annual precipitation from ensemble $\mathrm{AO}$ with that from ensemble ALO. In each plot, only icefree land points for which the mean precipitation from ensemble ALO exceeds $0.1 \mathrm{~mm} /$ day are considered.

Fig. 9 Breakdown of the contributions of oceanic, atmospheric, and land surface processes to precipitation variance, assuming a linear framework. Top left: precipitation variance in the absence of land-atmosphere feedback $\left(\sigma_{\mathrm{AO}}^{2}\right)$. Top right: The fraction of the precipitation variance induced by variable SSTs $\left(X_{O}\right.$ from $(3)$ ). Bottom left: The fraction of the precipitation variance induced by chaotic atmospheric dynamics $\left(1-X_{O}\right)$. Bottom right: Amplification of variance due to landatmosphere feedback $\left(\sigma_{\mathrm{ALO}}^{2} / \sigma_{\mathrm{AO}}^{2}\right)$.

Fig. 10 Scatter plot showing coherence index $\left(\Omega_{P}(\right.$ ALO $\left.)\right)$ versus land surface amplification factor $\left(a_{L}\right)$. Each point represents an ice-free land point for which the mean annual precipitation in ensemble ALO exceeds 0.1 $\mathrm{mm} /$ day.

Fig. 11 a. Map of Budyko's dryness index, as computed with (15) using the climatological mean fluxes derived from ensemble ALO. b. Scatter plot showing how $a_{L}$ varies with $\phi$.

Fig. 12 Top: Value of $\Omega_{P}$ (ALO) for boreal summer (JJA). Bottom: Same, but for boreal winter (DJF).

Fig. 13 Top left: Value of $\Omega_{P}$ from ensemble ALOX (in which land and ocean boundary conditions have realistic low frequency variations but are nevertheless prescribed) for boreal summer (JJA). Top right: Same, but for boreal winter (DJF). Bottom left: Differences between $\Omega_{P}$ from ensemble ALOX and that from ensemble ALO, indicating the added potential predictability stemming from land surface processes (JJA). Bottom right: Same, but for boreal winter (DJF).

Fig. 14 Top: Variation of mean evaporation rate (mm/day) from ALOX with relative humidity in the surface boundary layer, JJA. Bottom: Variation of $\Omega_{E}$ from ALOX with relative humidity in the surface boundary layer, JJA.

Fig. 15 Relative humidity in the surface layer. Dots indicate those grid cells for which the $\Omega_{P}$ calculated for ensemble ALOX exceeds that calculated for ensemble ALO by 0.3 . 


\begin{tabular}{|c|c|c|c|c|}
\hline $\begin{array}{l}\text { Experiment } \\
\text { (Ensemble) } \\
\text { Identifier }\end{array}$ & $\begin{array}{l}\text { \# of Simu- } \\
\text { lations in } \\
\text { Ensemble } \\
\end{array}$ & $\begin{array}{r}\text { Length of } \\
\text { Each Simu- } \\
\text { lation } \\
\end{array}$ & $\begin{array}{l}\text { Total } \\
\text { Years }\end{array}$ & $\begin{array}{l}\text { Experiment } \\
\text { Description }\end{array}$ \\
\hline A & 4 & 200 years & 800 & $\begin{array}{l}\text { Prescribed, } \\
\text { Climatological } \\
\text { Land; } \\
\text { Climatological } \\
\text { Ocean }\end{array}$ \\
\hline $\mathrm{AL}$ & 4 & 200 years & 800 & $\begin{array}{l}\text { Interactive land; } \\
\text { Climatological } \\
\text { Ocean }\end{array}$ \\
\hline $\mathrm{AO}$ & 16 & 45 years & 720 & $\begin{array}{l}\text { Prescribed, } \\
\text { Climatological } \\
\text { Land; } \\
\text { Interannually- } \\
\text { Varying Ocean }\end{array}$ \\
\hline $\mathrm{ALO}$ & 16 & 45 years & 720 & $\begin{array}{l}\text { Interactive land; } \\
\text { Interannually- } \\
\text { Varying Ocean }\end{array}$ \\
\hline ALOX & 16 & 45 years & 720 & $\begin{array}{l}\text { Prescribed, } \\
\text { Interannually- } \\
\text { Varying Land; } \\
\text { Interannually- } \\
\text { Varying Ocean }\end{array}$ \\
\hline
\end{tabular}

Table 1: Summary of ensembles performed for the present analysis. 

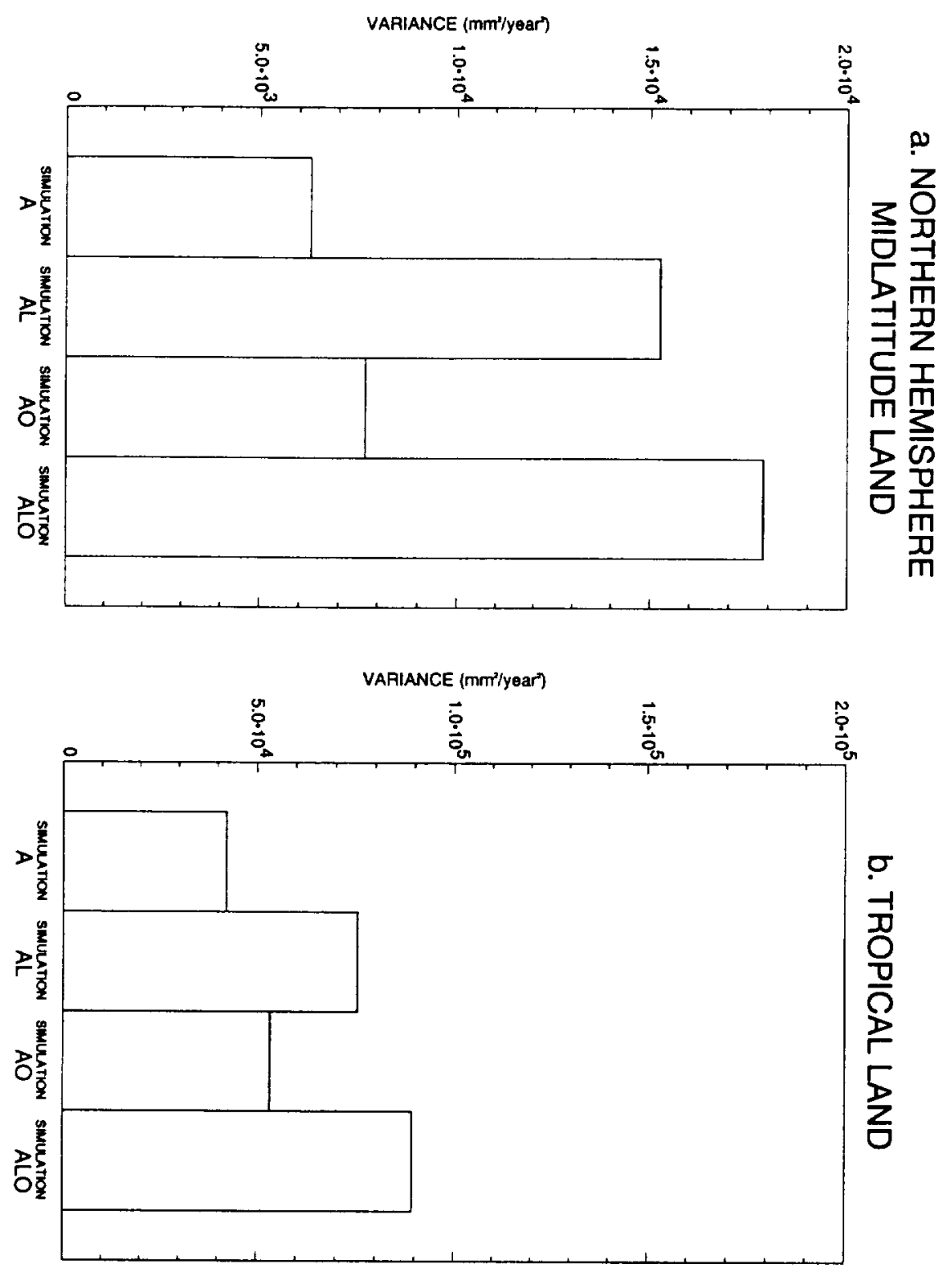

Figure 1: Histogram showing, for each simulation in the KS95 study, the variance of annual precipitation averaged over (a) northern hemisphere midlatitude land $\left(30^{\circ} \mathrm{N}-50^{\circ} \mathrm{N}\right)$ and (b) tropical land $\left(10^{\circ} \mathrm{S}-10^{\circ} \mathrm{N}\right)$. 

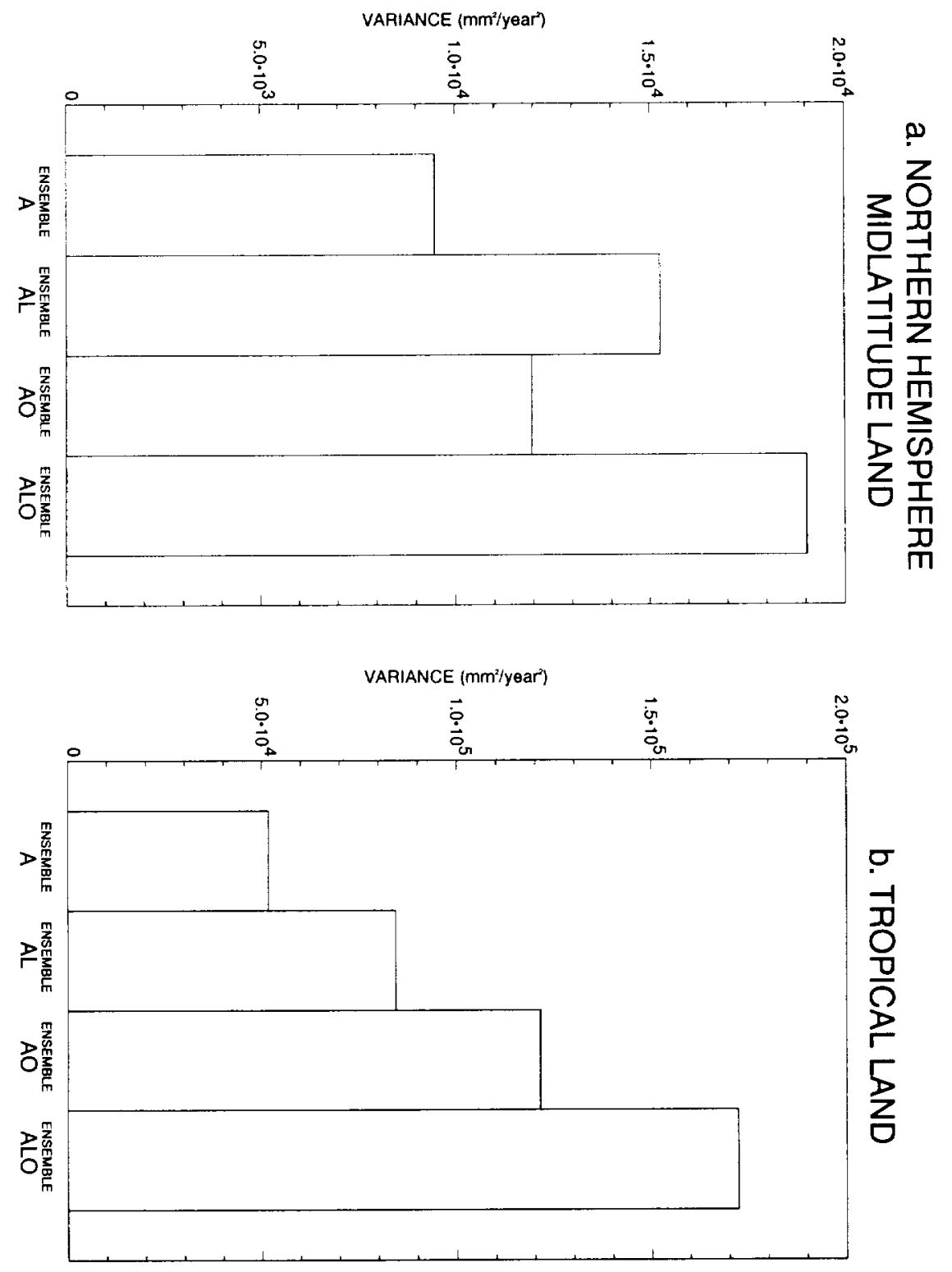

Figure 2: Histogram showing, for each of the ensembles examined in the current study, the variance of annual precipitation averaged over (a) northern hemisphere midlatitude land $\left(30^{\circ} \mathrm{N}-50^{\circ} \mathrm{N}\right)$ and $(\mathrm{b})$ tropical land $\left(10^{\circ} \mathrm{S}-10^{\circ} \mathrm{N}\right)$. 

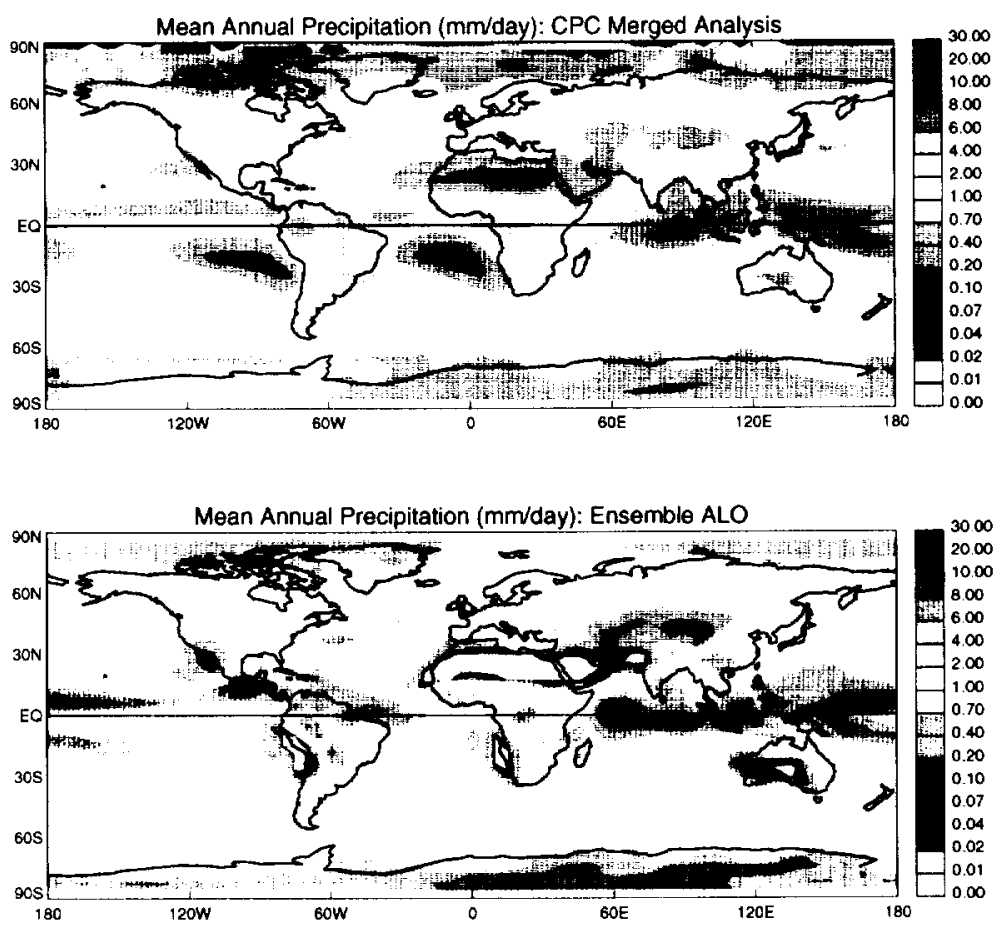

Figure 3: Top: Annual mean precipitation (mm/day) from the CPC Merged Analysis of Precipitation (CMAP, satellites and gauges only) [Xie and Arkin, 1997]. Bottom: Annual mean precipitation (mm/day), as computed from the 720 years of data from ensemble ALO. 

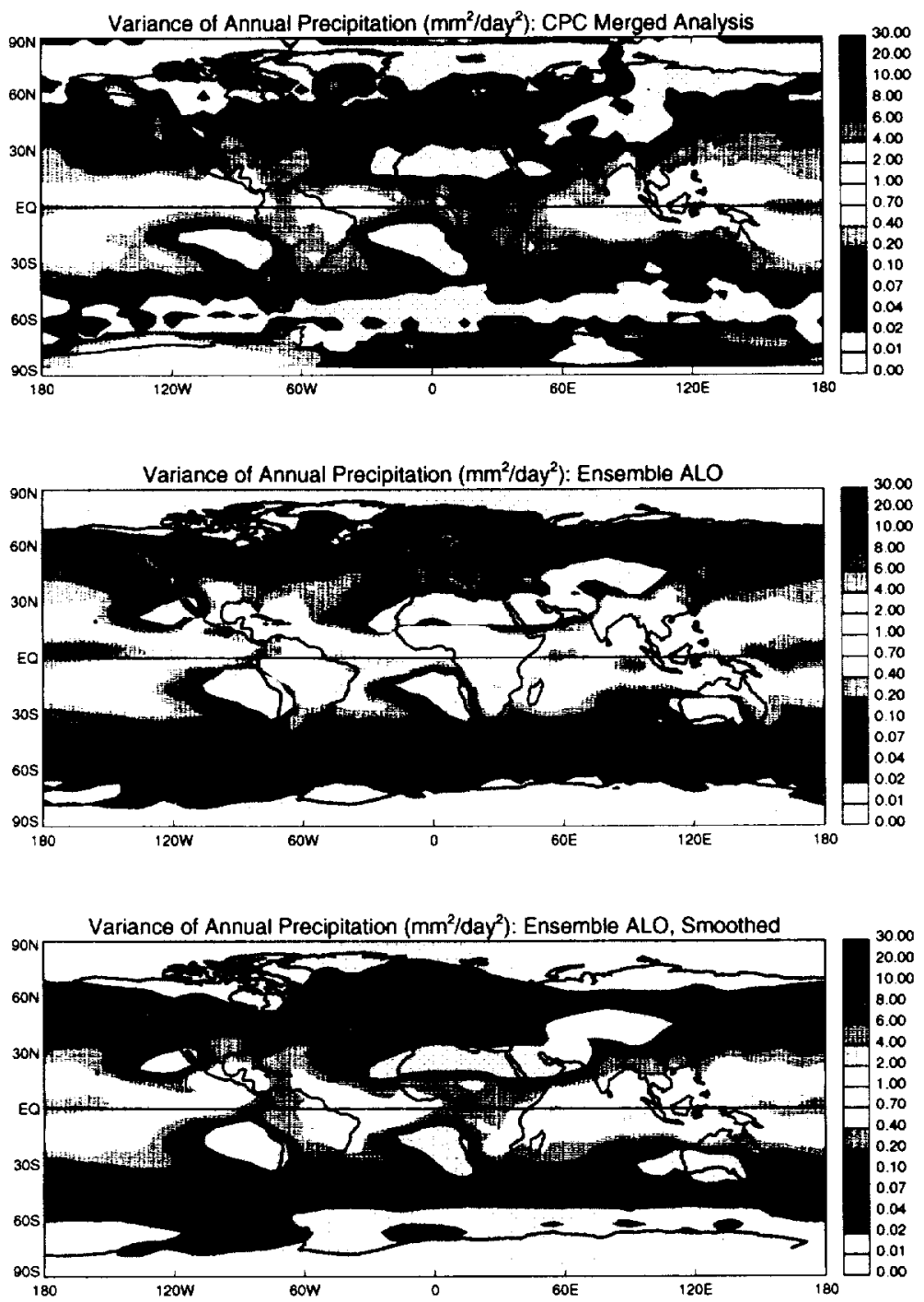

Figure 4: Top: Variance of annual precipitation $\left(\mathrm{mm}^{2} / \mathrm{day}^{2}\right)$ calculated from the CPC Merged Analysis of Precipitation (CMAP) [Xie and Arkin, 1997]. Middle: Variance of annual precipitation $\left(\mathrm{mm}^{2} / \mathrm{day}^{2}\right)$, as computed from the 720 years of data from ensemble ALO. Bottom: Variance of annual precipitation $\left(\mathrm{mm}^{2} / \mathrm{day}^{2}\right)$ from ensemble ALO, computed after first smoothing each annual field with a 9 -point filter. 


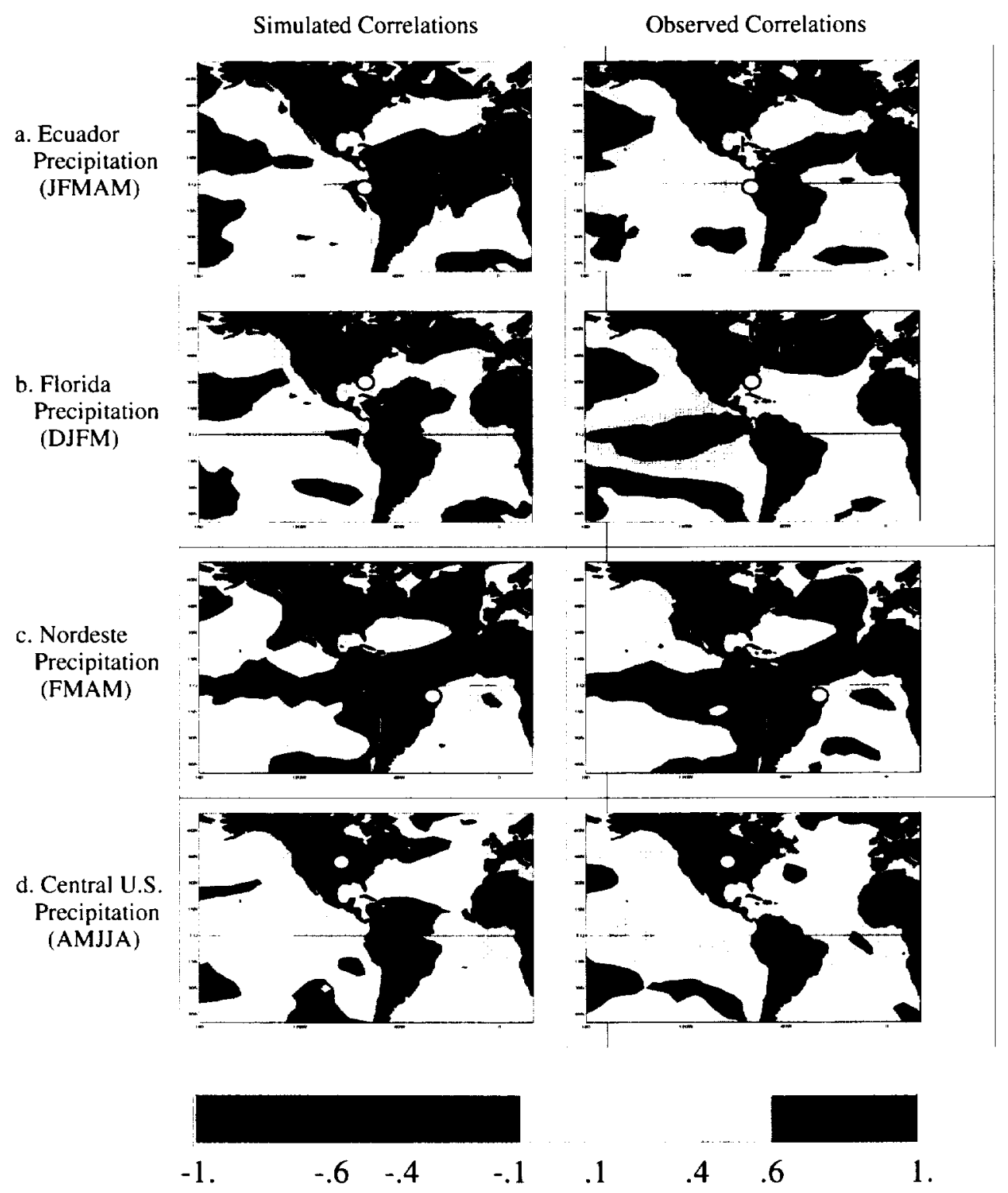

Figure 5: Simulated and observed correlations, $r$, between SST anomlies (averaged over the months indicated) and concurrent precipitation anomalies at four representative sites: (a) Ecuador; (b) Florida (including additional gulf stations for the observational analysis); (c) northeast Brazil; and (d) the central United States. The precipitation data used to generate the observed correlations are courtesy of Dr. Todd Mitchell of the University of Washington. 


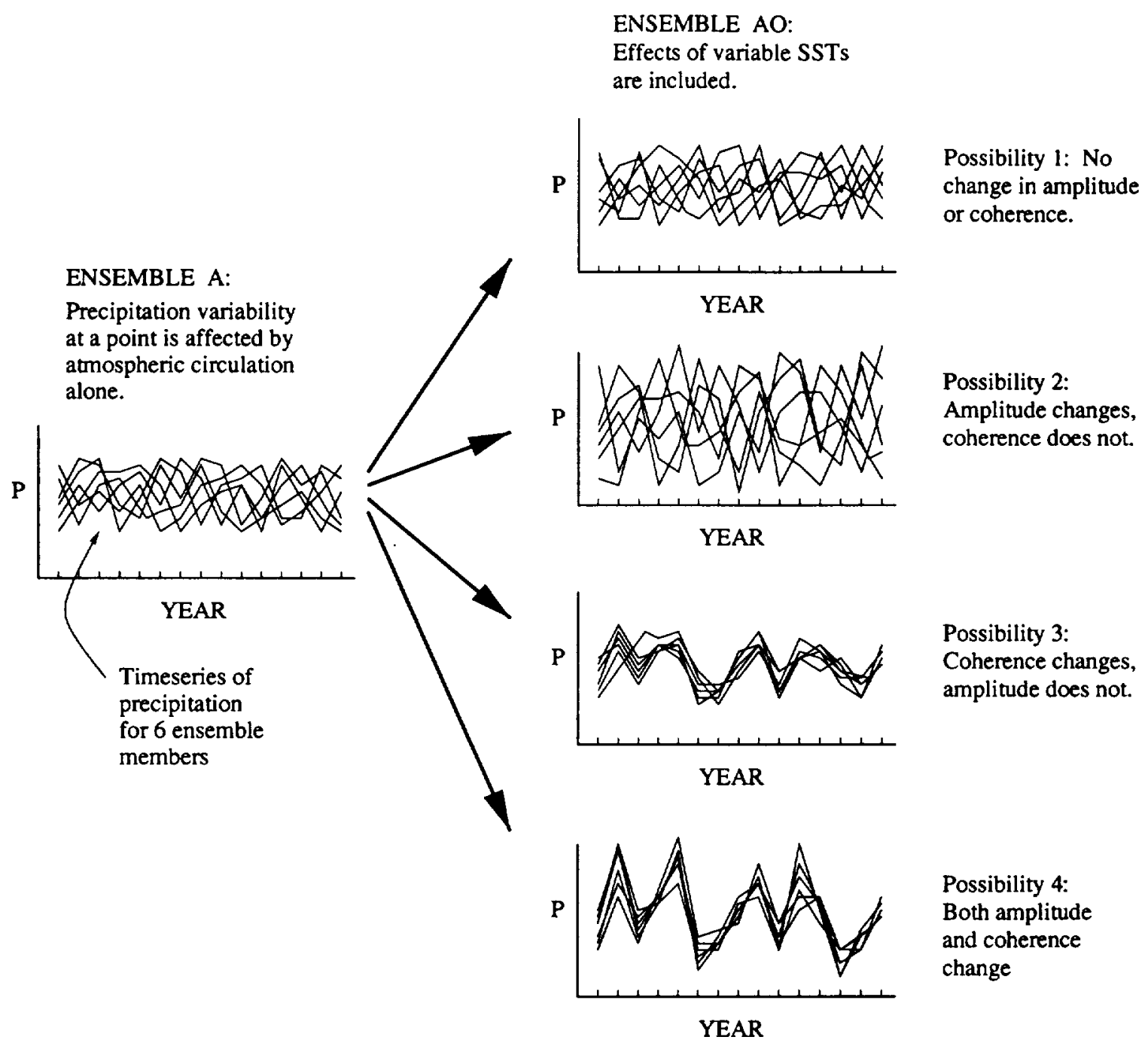

Figure 6: Illustration of the ways by which the inclusion of time-varying sea surface temperatures can affect precipitation variability at a given point. The timeseries shown are idealized; they do not represent actual data from the ensembles. 


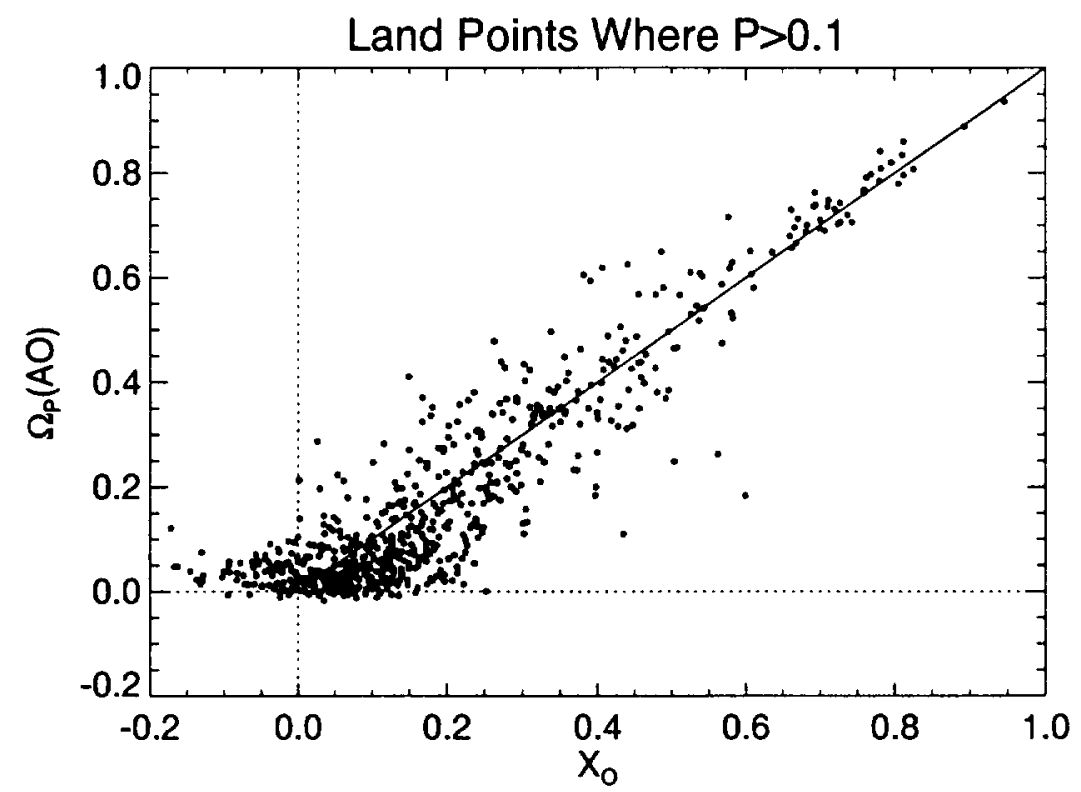

Figure 7: Scatter plot of amplitude index $\left(X_{O}\right)$ versus coherence index $\left(\Omega_{P}(A O)\right)$ as diagnosed from ensembles $\mathrm{A}$ and $\mathrm{AO}$. Each point in the plot represents a land surface grid cell with an average precipitation exceeding $0.1 \mathrm{~mm} /$ day. 

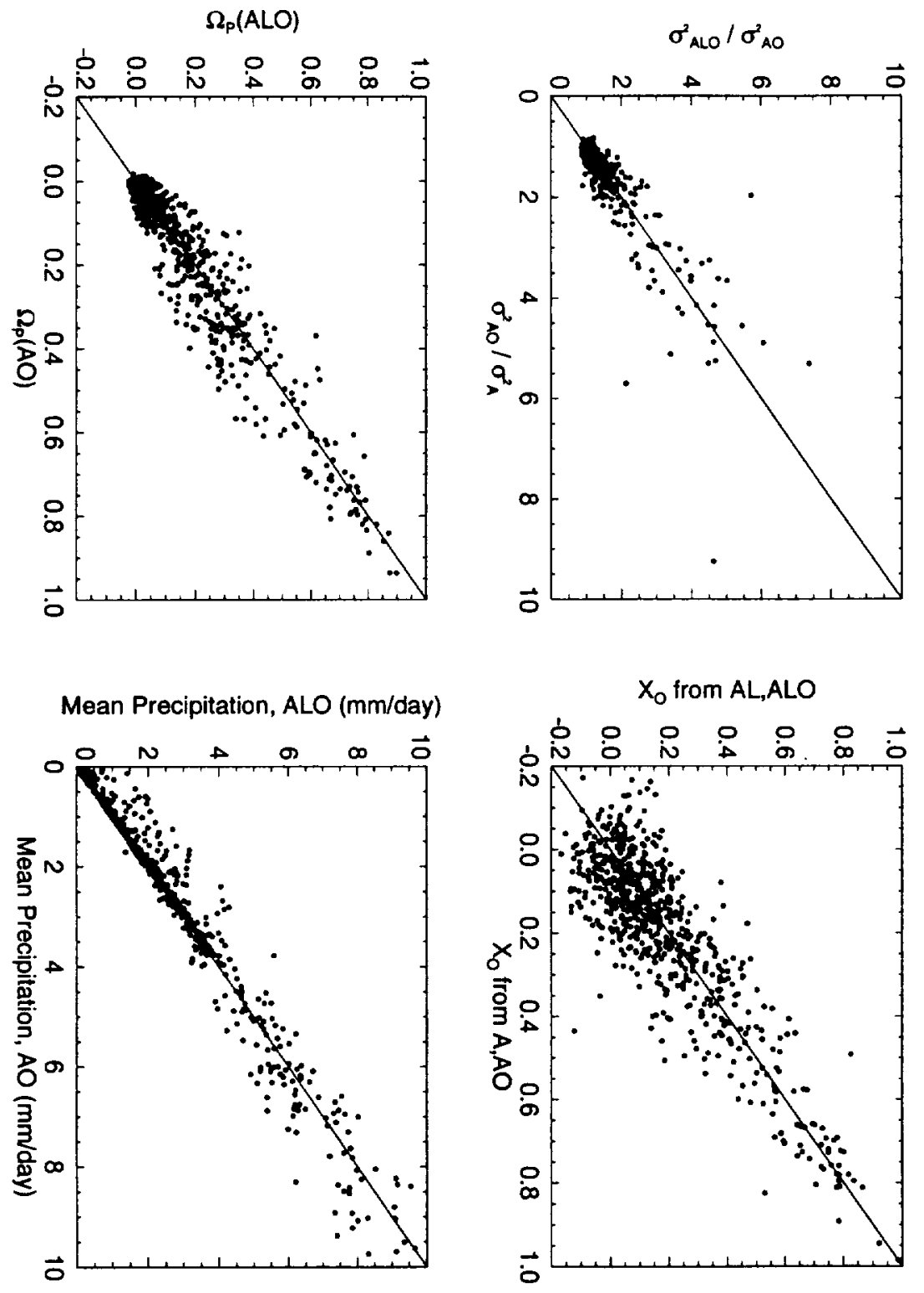

Figure 8: Top left: Test of linearity through a comparison of $\frac{\sigma_{A L}^{2}}{\sigma_{A}^{2}}$ with $\frac{\sigma_{A L O}^{2}}{\sigma_{A O}^{2}}$, calculated with annual means. Top right: Test of linearity through a comparison of $X_{O}$ from (3) with $X_{O}$ from (13), calculated with annual means. Bottom left: Test of linearity through a comparison of $\Omega_{P}(A L)$ with $\Omega_{P}(A L O)$, calculated with annual means. Bot fom right: Test of linearity through a comparison of mean annual precipitation from ensemble $\mathrm{AO}$ with that from ensemble ALO. In each plot, only ice-free land points for which the mean precipitation from ensemble ALO exceeds $0.1 \mathrm{~mm} /$ day are considered. 

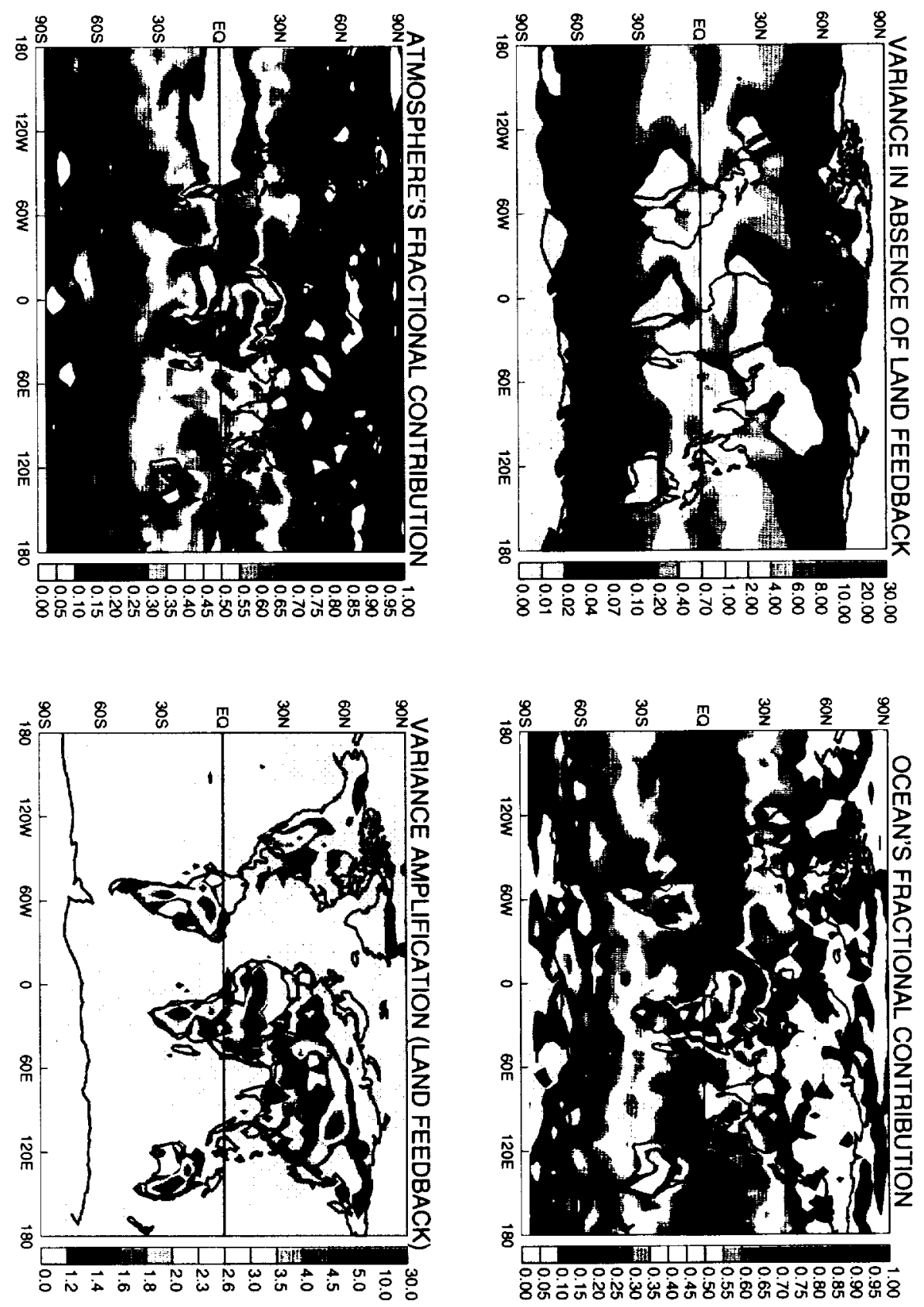

Figure 9: Breakdown of the contributions of oceanic, atmospheric, and land surface processes to precipitation variähce, assuming a linear framework. Top left: precipitation variance in the absence of land-atmosphere feedback $\left(\sigma_{\mathrm{AO}}^{2}\right)$. Top right: The fraction of the precipitation variance induced by variable SSTs $\left(X_{O}\right.$ from (3)). Bottom left: The fraction of the precipitation variance induced by chaotic atmospheric dynamics $\left(1-X_{O}\right)$. Bottom right: Amplification of variance due to land-atmosphere feedback $\left(\sigma_{\mathrm{A} \text { In }}^{2} / \sigma_{\mathrm{A} n}^{2}\right)$. 


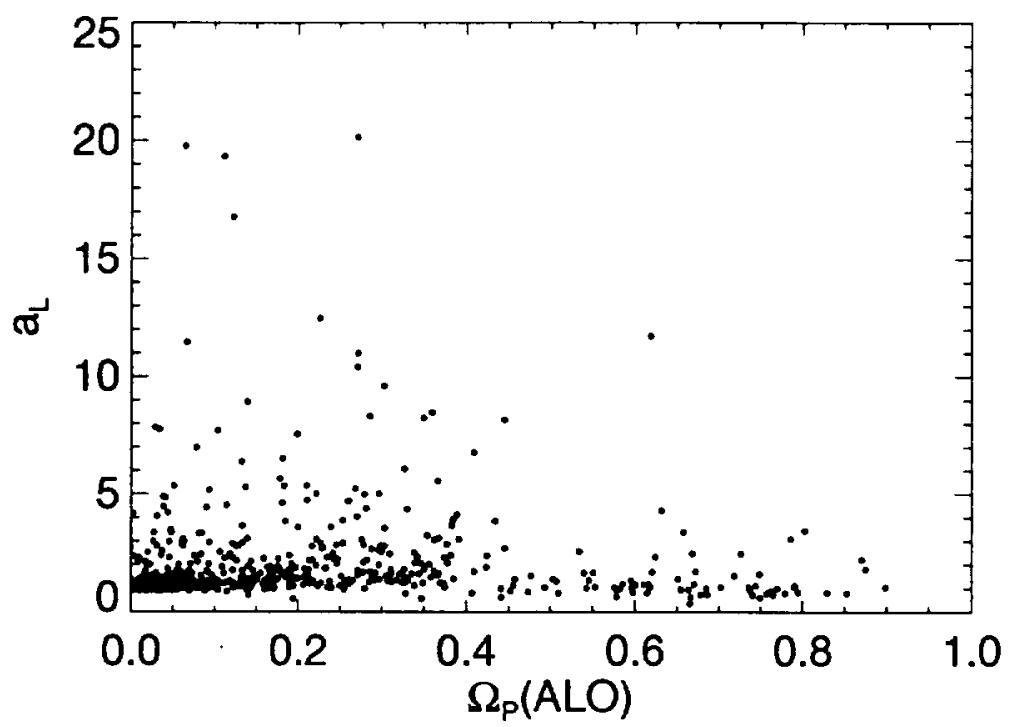

Figure 10: Scatter plot showing coherence index $\left(\Omega_{P}(\mathrm{ALO})\right)$ versus land surface amplification factor $\left(a_{L}\right)$. Each point represents an ice-free land point for which the mean annual precipitation in ensemble ALO exceeds $0.1 \mathrm{~mm} /$ day. 

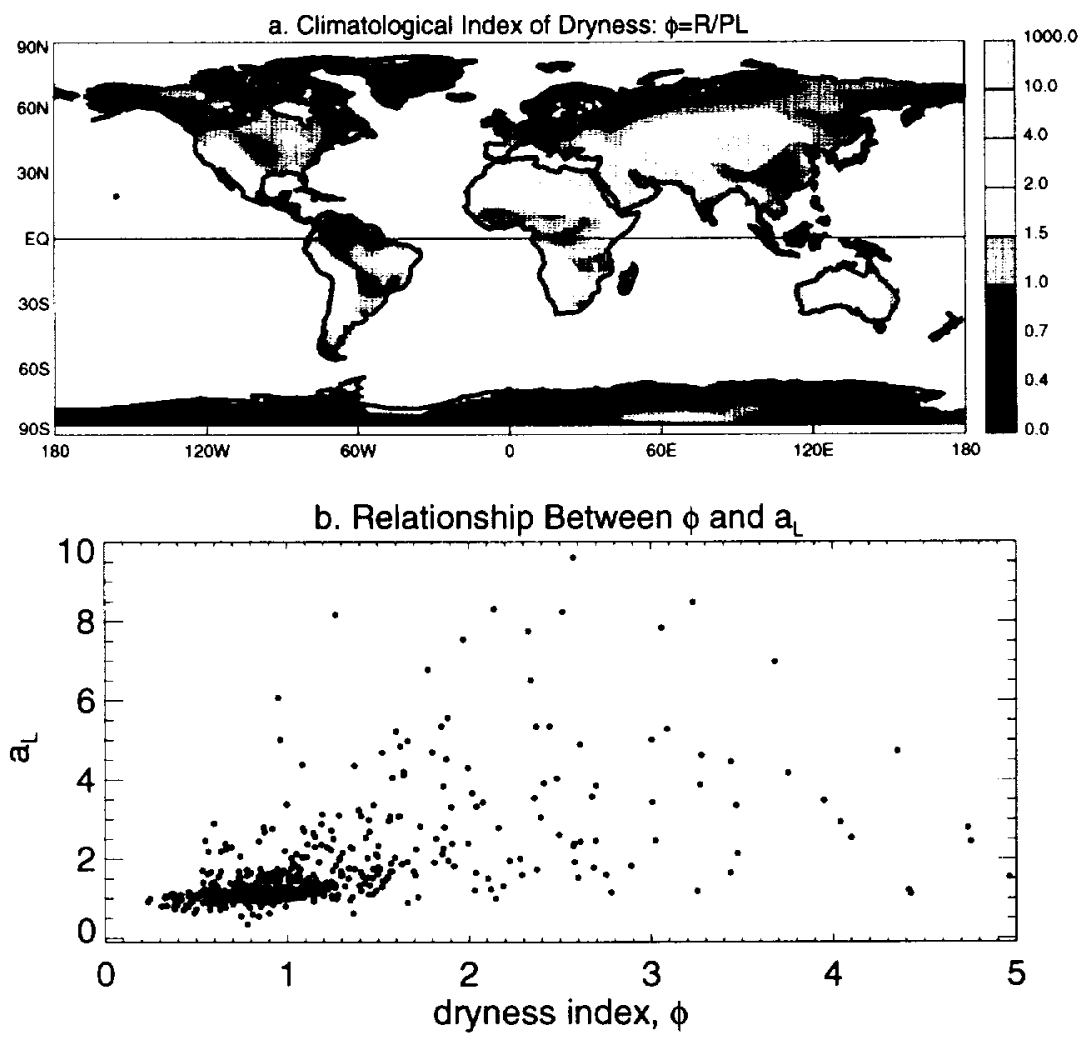

Figure 11: a. Map of Budyko's dryness index, as computed with (15) using the climatological mean fluxes derived from ensemble ALO. b. Scatter plot showing how $a_{L}$ varies with $\phi$. 

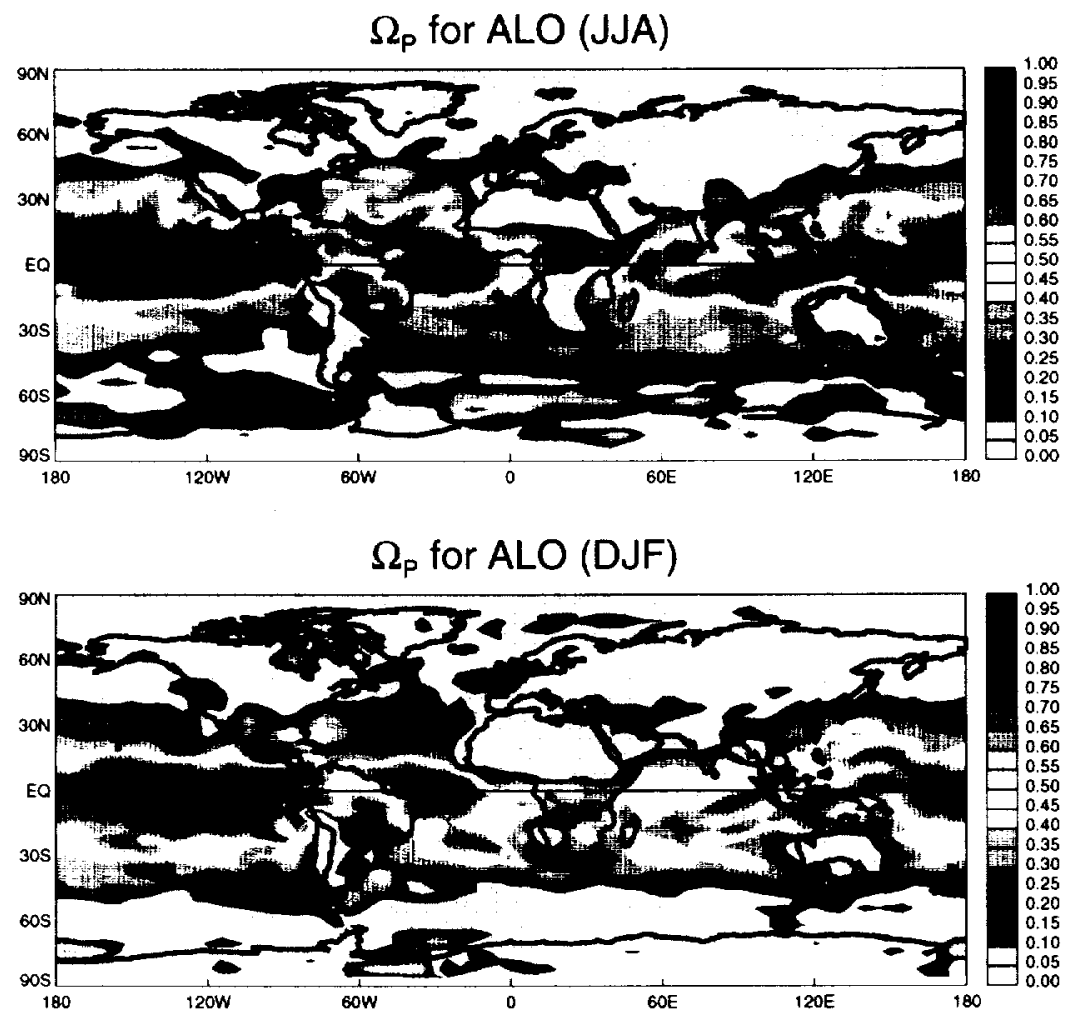

Figure 12: Top: Value of $\Omega_{P}$ ALO for boreal summer (JJA). Bottom: Same, but for boreal winter (DJF). 

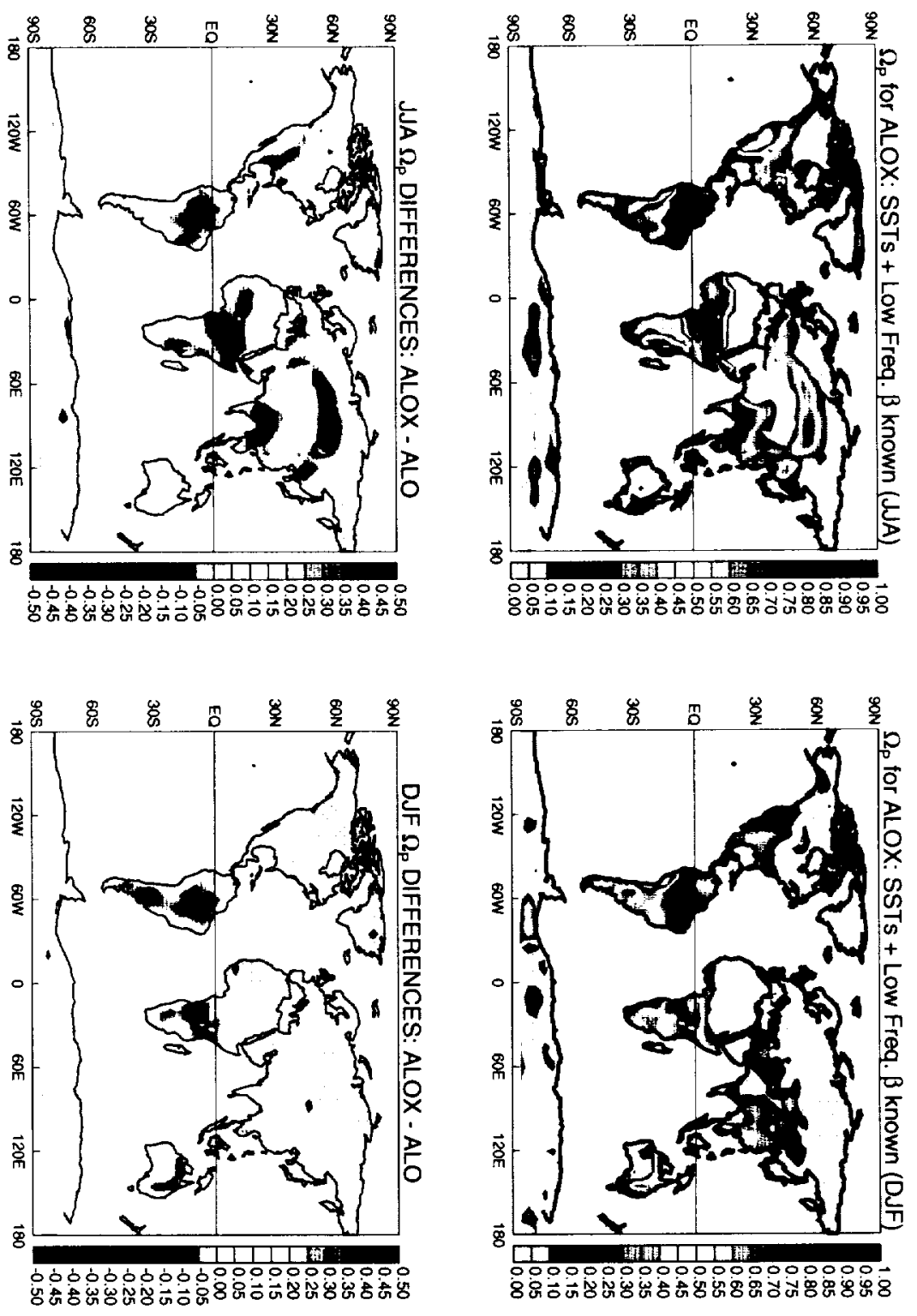

Figure 13: Top left: Value of $\Omega_{P}$ from ensemble ALOX (in which land and ocean boundary conditions have realistic low frequency variations but are nevertheless prescribed) for boreal summer (JJA). Top right: Same, but for boreal winter (DJF). Bottom left: Differences between $\Omega_{P}$ from ensemble ALOX and that from ensemble ALQ1 indicating the added potential predictability stemming from land surface processes (JJA). Bottom right: Same, but for boreal winter (DJF). 

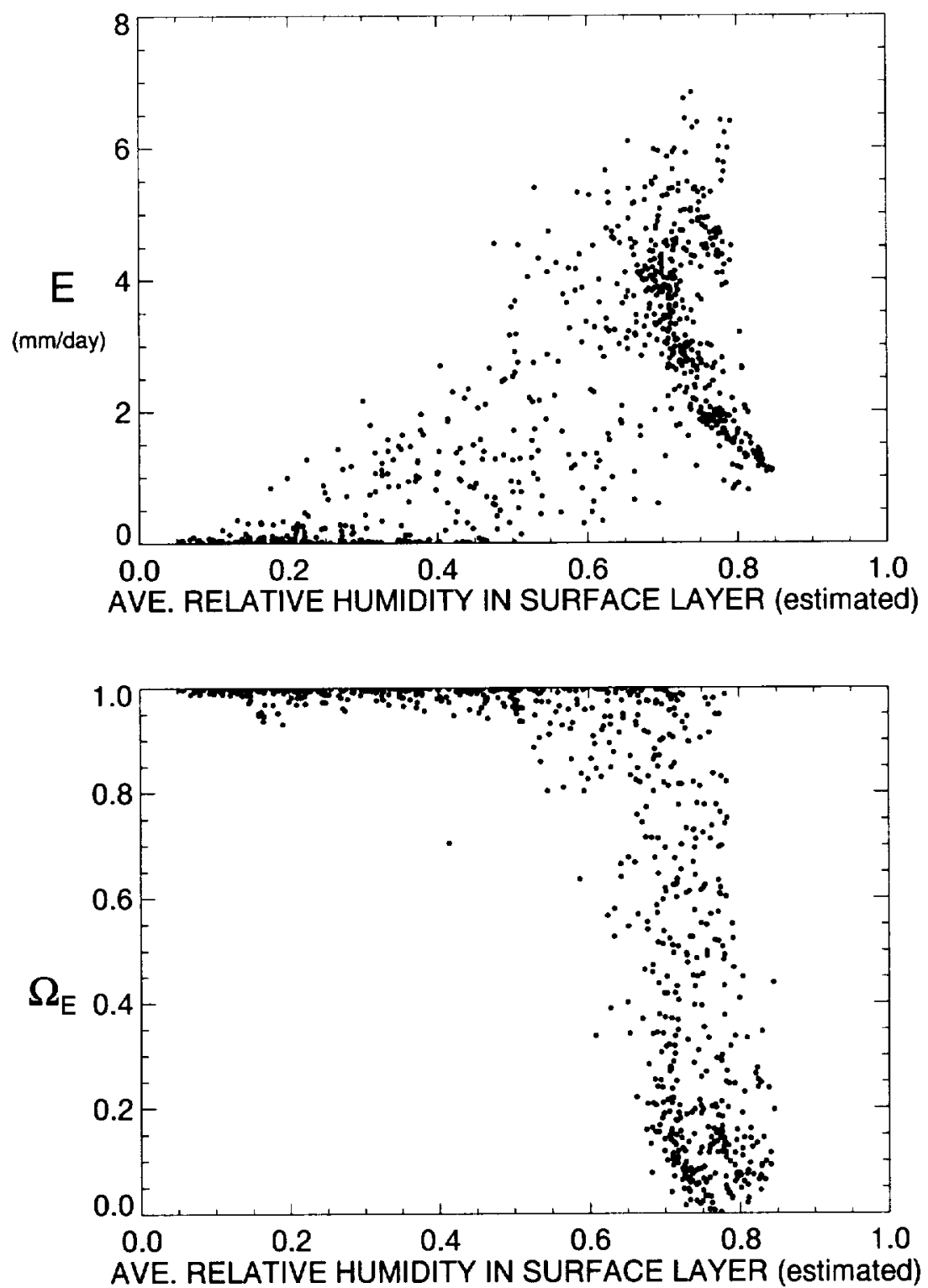

Figure 14: Top: Variation of mean evaporation rate (mm/day) from ALOX with relative humidity in the surface boundary layer, JJA. Bottom: Variation of $\Omega_{E}$ from ALOX with relative humidity in the surface boundary layer, JJA. 

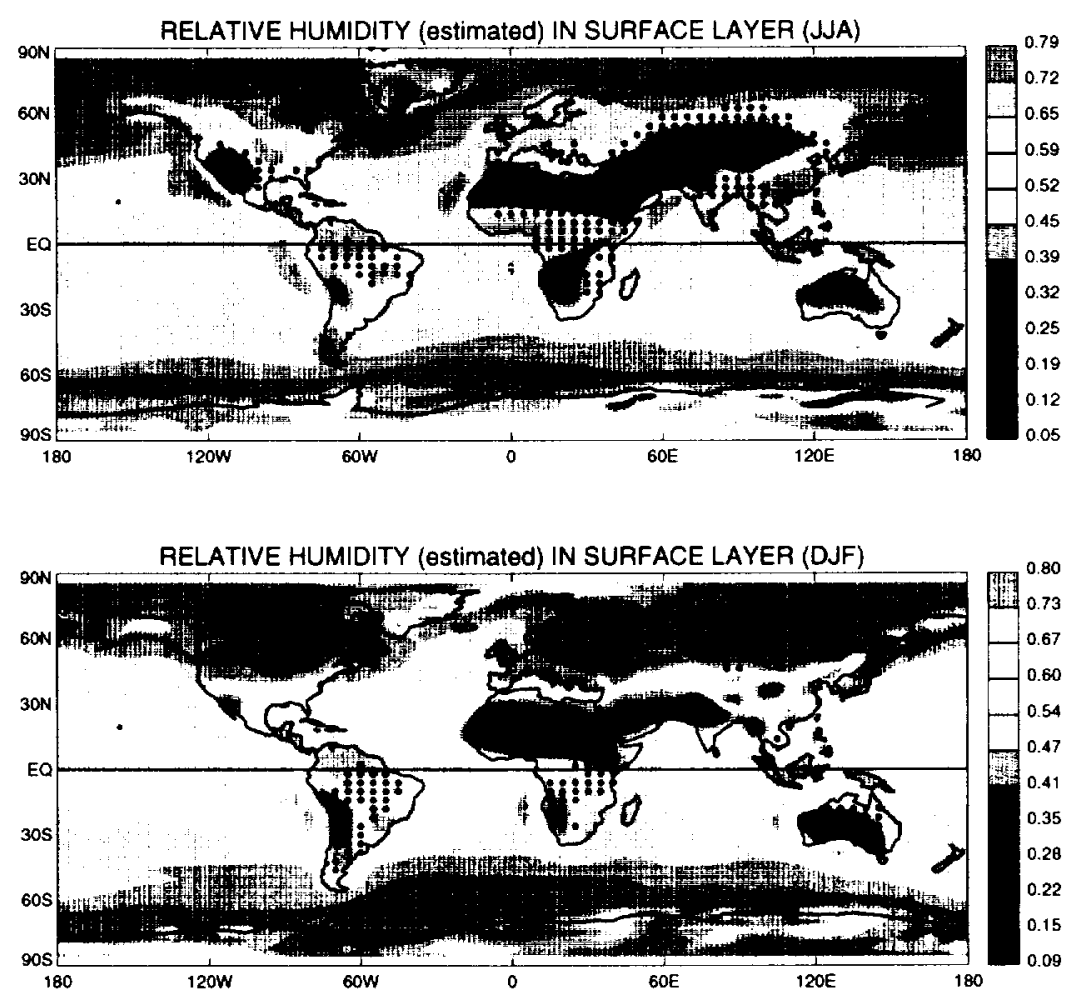

Figure 15: Relative humidity in the surface layer. Dots indicate those grid cells for which the $\Omega_{P}$ calculated for ensemble ALOX exceeds that calculated for ensemble ALO by 0.3 . 